\title{
1 A Predictive Model of the Temperature-Dependent Inactivation of Coronaviruses
}

2 Te Faye Yap, ${ }^{\mathrm{a}}$ Zhen Liu, ${ }^{\mathrm{a}, \dagger}$ Rachel A. Shveda, ${ }^{\mathrm{a}, \dagger}$ Daniel J. Preston ${ }^{\mathrm{a}, *}$

$4 \quad{ }^{\mathrm{a} D e p a r t m e n t}$ of Mechanical Engineering, Rice University, 6100 Main St., Houston, TX 77006

5

$6 \quad{ }^{\dagger}$ Denotes equal contribution

$7 \quad$ *To whom correspondence should be addressed: djp@rice.edu

9 ABSTRACT

10 The COVID-19 pandemic has stressed healthcare systems and supply lines, forcing medical doctors to

11 risk infection by decontaminating and reusing medical personal protective equipment intended only for a

12 single use. The uncertain future of the pandemic is compounded by a lack of data on the ability of the

13 responsible virus, SARS-CoV-2, to survive across various climates, preventing epidemiologists from

14 accurately modeling its spread. However, existing data on the thermal inactivation of related

15 coronaviruses can provide insights enabling progress towards understanding and mitigating COVID-19.

16 This paper describes a thermodynamic model that synthesizes data from the literature to accurately

17 predict the temperature-dependent inactivation of coronaviruses. The model provides much-needed

18 thermal sterilization guidelines for personal protective equipment, including masks, and will also allow

19 epidemiologists to incorporate temperature into models forecasting the spread of coronaviruses across

20 different climates and seasons. 
22 The COVID-19 pandemic has spread quickly and overwhelmed medical facilities worldwide, often

23 resulting in a lack of intensive care beds and ventilators. These circumstances have forced doctors to

24 decide which patients to provide with life-saving equipment—and which patients to leave without. The

25 shortages have not only affected patients; facing a lack of masks, face shields, gowns, and other typically-

26 disposable personal protective equipment (PPE), medical workers have had to reuse PPE or work without

27 proper protection. As a result, many of them have been infected with SARS-CoV-2, the virus that causes

28 COVID-19, despite the potential for effective sterilization techniques, including dry heat sterilization.

29 Furthermore, as COVID-19 spreads to almost every region of the globe, epidemiologists need to know

30 how long the virus survives in different climates to precisely predict where to focus limited resources,

31 how to model further spread, and how to predict future seasonal flare-ups.

During previous viral outbreaks, regional shortages of personal protective equipment (PPE) led

34 researchers to explore decontamination procedures that might allow PPE to be reused safely. ${ }^{1,2}$ Facing an unprecedented nationwide lack of PPE brought on by the COVID-19 pandemic, medical workers have begun implementing these procedures: For example, The University of Nebraska Medical Center in

37 Omaha began attempting in March 2020 to reuse masks after decontamination with ultraviolet (UV)

38 irradiation. ${ }^{3}$ However, UV decontamination faces several drawbacks, including an inability to kill viruses

39 trapped within crevices that are not illuminated and a lack of availability in clinics in low-income areas

40 and in most peoples' homes. ${ }^{4}$ Other methods of decontamination, namely steam sterilization, alcohol

41 washing, and bleach washing, are useful for items like glassware and other durable materials, but have

42 been reported to degrade surgical masks and other delicate PPE not intended for reuse. ${ }^{2,5,6}$ Dry heat

43 sterilization, on the other hand, can be performed almost anywhere (including in home ovens intended for

44 cooking), and viruses inside of crevices or within fabrics are easily inactivated. In addition, while dry heat

45 sterilization is often performed at $160{ }^{\circ} \mathrm{C}$ or higher, it can effectively inactivate viruses at much lower

46 temperatures as well (albeit over longer periods of time), enabling sterilization and reuse of delicate PPE 
47 intended for disposal after a single use. ${ }^{7}$ However, at this time, appropriate dry heat sterilization 48 guidelines for single-use PPE do not exist.

50 Meanwhile, virus transmission has been linked to both seasonal and regional variations in climate, where 51 colder atmospheric temperatures typically lead to longer virus lifetimes outside of their hosts. This effect 52 has been reported for both influenza ${ }^{8,9}$ and the common cold, ${ }^{10}$ and even SARS-CoV-1 has been shown to 53 survive longer at lower temperatures. ${ }^{11}$ Epidemiologists require more information on the lifetime of

54 SARS-CoV-2 as a function of atmospheric temperature in order to accurately model the spread of

55 COVID-19. Furthermore, understanding this temperature-dictated inactivation time could help predict

56 whether the autumn and winter will bring a resurgence of cases as the colder weather returns, following a 57 similar trend to that of the seasonal flu. ${ }^{12}$ In this work, we describe a simple model based on the rate law and Arrhenius equation for the thermal inactivation of a range of coronaviruses, essentially treating the viruses as macromolecules that undergo

61 thermal denaturation. Our model predicts the time required to achieve a desired log-scale reduction in 62 viable virions (e.g. by a factor of $10^{6}$ as typically used for sterilization ${ }^{13-16}$ ) at a given temperature. Based 63 on our model, we provide conservative guidelines for dry heat sterilization of coronaviruses that may be used to safely enable sterilization of the SARS-CoV-2 coronavirus at temperatures achievable in commonly available equipment like home-use cooking ovens and rice cookers. We also estimate, based

66

67 on data for human coronaviruses similar in structure and inactivation behavior ${ }^{17}$ to SARS-CoV-2, including SARS-CoV-1, the inactivation rate of human coronaviruses in various climates. We believe these results will be of extreme importance to epidemiologists in predicting the regionally-dependent lifetime of the SARS-CoV-2 virus as well as the severity of the resurgence of COVID-19 that we may face this upcoming autumn and winter. 


\section{RESULTS}

74 Reports in the literature describe the inactivation of many strains of viruses over time, with experiments in different reports conducted over a range of temperatures, providing abundant data upon which a predictive analytical model capturing the influence of thermal effects on virus inactivation may be constructed. In this work, we focused specifically on the inactivation of coronaviruses, a group of enveloped viruses that contain positive sense single-stranded RNA and are often responsible for respiratory or gastrointestinal diseases in mammals and birds. ${ }^{18}$ Specifically, we focused on five types of coronaviruses, with subdivisions in data between types of viruses based on (i) strains of each virus, (ii) $\mathrm{pH}$ levels, and (iii) relative humidity conditions during experiments, resulting in thirteen sets of data (Figure 1(a)). These viruses include: (i) Severe Acute Respiratory Syndrome Coronavirus (SARS CoV$1) ;{ }^{19-21}$ (ii) Middle East Respiratory Syndrome Coronavirus (MERS-CoV); ${ }^{22,23}$ (iii) Transmissible

84 Gastroenteritis Virus (TGEV); ${ }^{24}$ (iv) Mouse Hepatitis Virus (MHV); ${ }^{25,26}$ and (v) Porcine Epidemic

85 Diarrhea Virus (PEDV). ${ }^{27}$ The first two viruses are highly pathogenic human coronaviruses that cause life-threatening respiratory diseases; SARS-CoV-2, the virus responsible for the COVID-19 pandemic, is

87 closely related to SARS-CoV-1 and exhibits many chemical and biological similarities. ${ }^{28}$ The latter three viruses are zoonotic viruses known to cause mild to severe illnesses in humans. In each of these studies evaluating thermal inactivation characteristics of coronaviruses, viral inocula were exposed to different temperatures at varying time intervals. Samples were prepared by either suspending the viral stock in an

91 appropriate test tube medium or depositing on a material surface. After exposure to different 92 temperatures, samples on surfaces were recovered to a minimum essential medium. Either a plaque assay 93 or a $50 \%$ tissue culture infectious dose $\left(\mathrm{TCID}_{50}\right)$ assay was used to evaluate the infectious titer; we 94 converted $\mathrm{TCID}_{50}$ results to number of plaque forming units by multiplying by 0.69 based on theory, as 95 performed in prior work. ${ }^{29-31}$ Some of these reports also explored on the effects of $\mathrm{pH}$ and relative 96 humidity on viral infectivity. ${ }^{24,27,32}$ 
The inactivation behavior of microbes can be described accurately by the rate law. ${ }^{33}$ Non-first-order rate laws have been applied to inactivation of some microbes, ${ }^{34-36}$ particularly bacteria with heterogeneous populations, ${ }^{37}$ but the inactivation of most viruses - including the viruses considered in our analysisfollows a first-order reaction, with viable virions as products and inactivated virions as reactants (Eq. 1):

$$
[C]=\left[C_{0}\right] e^{-k t}
$$

102 The majority of primary experimental data for the inactivation of viruses is reported in plots of the log of concentration $\ln ([C])$ as a function of time. The rate constant, $k$, can be determined from the primary data by fitting a line to data taken at a given temperature, $T$, and calculating the slope, $k=\Delta \ln ([C]) / \Delta t$. Each of these pairs of $(k, T)$ equate to one data point in Figure 1(a). We fitted straight lines to the primary data for each of the viruses studied here; these linear fits are included in the Supporting Information.

Virus inactivation occurs primarily due to thermal denaturation of the proteins that comprise each virion.

109 The temperature dependence of this thermal denaturation process is captured by the Arrhenius relationship, ${ }^{38}$ which yields a linear relationship between $\ln (k)$ and $1 / T$ (Eq. 2$)$ :

$$
\ln (k)=-E_{a} / R T+\ln (A)
$$

111 where $R$ is the gas constant, $E_{a}$ is the activation energy associated with inactivation of the virus (i.e., the 112 energy barrier that must be overcome for protein denaturation), and $A$ is the frequency factor. Therefore, 113 in Figure 1(a), we applied linear fits to the data to enable continuous prediction of the reaction rates over 114 the full range of temperatures. The activation energy, $E_{a}$, and natural $\log$ of the frequency factor, $\ln (A)$, 115 were calculated for each virus by equating $-E_{\mathrm{a}} / R$ and $\ln (A)$ from Eq. 2 with the slopes and intercepts from 116 the linear fits in Figure 1(a), respectively, and are plotted in Figure 1(b). The correlation between $\ln (A)$ 117 and $E_{a}$ indicates a thermal denaturation process, ${ }^{39}$ in agreement with our assertion that the coronaviruses 118 investigated here are inactivated primarily by thermally-driven protein denaturation. In fact, the slope and 119 intercept of a best-fit line applied to the data, for which we calculate $\left[\ln (A)=0.392 E_{\mathrm{a}}-5.43\right]$ from the 120 dataset used in this work, are nearly identical to the slopes and intercepts of $\left[\ln (A)=0.380 E_{\mathrm{a}}-5.27\right]^{39}$ and $121\left[\ln (A)=0.383 E_{\mathrm{a}}-5.95\right]^{40}$ reported in prior work on denaturation of tissues and cells. 

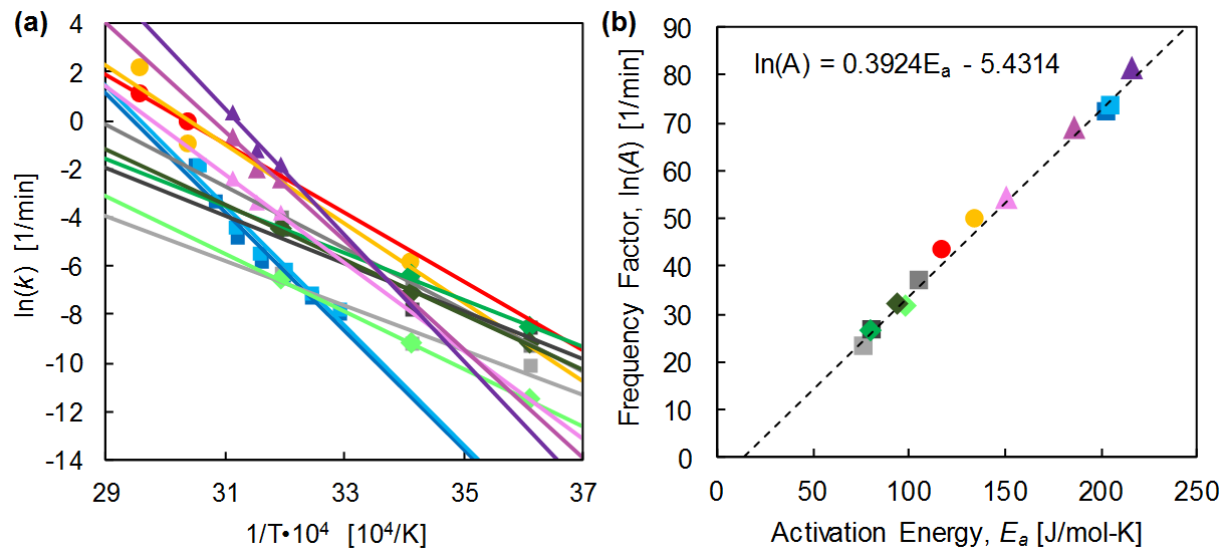

- SARS-CoV-1
MERS-CoV
- TGEV-D52
- TGEV-Purdue
- TGEV-RH20
- TGEV-RH50
- TGEV-RH80
MHV-RH20
MHV-RH50
- MHV-RH80
A PEDV-pH 7.2
A PEDV-pH 9.2
A PEDV-pH 10.2

123 Figure 1. Dependence of inactivation rate on temperature, compiled from literature on several strains 124 and under different humidity conditions for SARS-CoV-1, MERS-CoV, TGEV, MHV, and PEDV (a). Each

125 dataset has been fitted with a linear curve according to Eq. 2, and the resulting activation energy and 126 frequency factor were back-calculated from each linear fit according to Eq. 2 and plotted (b); the linear correlation between the log of frequency factor versus activation energy for the set of coronaviruses considered here supports our hypothesis that they are inactivated due to protein denaturation. ${ }^{39}$

The degree of inactivation of a pathogen is defined by the ratio of the concentration (amount) of a pathogen compared to its initial concentration, $[\mathrm{C}] /\left[\mathrm{C}_{0}\right]$, with varying levels of inactivation corresponding to rigor of sterilization reported in the literature, often in terms of orders of magnitude; an $n$ - $\log$

133 inactivation refers to a reduction in concentration of 10 raised to the $n$th power $\left([\mathrm{C}] /\left[\mathrm{C}_{0}\right]=10^{-n}\right)$.

134 Equations 1 and 2 combine to yield the time required to achieve an $n$-log reduction in a pathogen (Eq. 3):

$$
t_{n-\log }=-\frac{1}{A} e^{\left(\frac{E_{a}}{R T}\right)} \ln \left(10^{-n}\right)
$$

135 The US Food and Drug Administration recommends a 6-log reduction in concentration of a pathogen (i.e.

$136[\mathrm{C}] /\left[\mathrm{C}_{0}\right]=10^{-6}$ ) for sterilization. ${ }^{13-16}$ We use this value throughout the remainder of our analysis to 137 indicate sterilization times and lifetimes of viruses, although a more conservative value inserted into Eq. 3 138 would change all of the resulting predictions by a simple multiplicative factor of $\mathrm{n} / 6$ (e.g. to achieve a 12- 
$139 \log$ reduction in a virus would require doubling all of the times predicted in this work). The predictions 140 generated from Eq. 3 are plotted in Figure 2 and detailed in Tables 1 and 2.

142 Figure 2 shows the model predictions of thermal sterilization time as a function of temperature ranging 143 from room temperature to temperatures achievable using common heating devices. In Figure 2(a), all five 144 types of coronaviruses (subdivided according to virus strain and the experimental conditions of relative 145 humidity and $\mathrm{pH}$, as applicable) are plotted to show the variation across different conditions and types of 146 coronavirus. The plot in Figure 2(b) shows the same data, with the exception of data sourced from 147 Casanova, et al., ${ }^{11}$ due to potential experimental error (see Supporting Information, Section S3). The same 148 data from Figure 2(b) is replotted in Figure 2(c) with the sterilization time axis scaled linearly to 149 highlight the exponential dependence on the temperature. Figure 2(d) focuses solely on the two human 150 coronaviruses included in this work; SARS-CoV-1 and MERS-CoV exhibit a similar trend in thermal 151 degradation, and recent work has shown that SARS-CoV-2 behaves much like SARS-CoV-1. ${ }^{17}$

153 The data in Table 1 summarizes the maximum and average sterilization times required for inactivation of 154 all coronaviruses and the subset of human coronaviruses (SARS-CoV-1 and MERS-CoV) analyzed in this 155 work. The values displayed in the table were selected to demonstrate that thermal sterilization is feasible 156 at relatively low temperatures, albeit requiring longer sterilization times. The maximum coronavirus 157 sterilization time values are extracted from the data in Figure 2(a) to provide the most conservative 158 sterilization guidelines by taking the maximum values from predictions incorporating the full data set. 159 The geometric mean was used to calculate the average sterilization time for the same set of data. The data 160 shown in Figure 2(d) was used to calculate the maximum temperature for human coronavirus sterilization 161 time, and the geometric mean was used to calculate the average sterilization time. Meanwhile, Table 2 162 shows the time required for human coronaviruses to thermally denature outside a host under different 163 environmental temperatures, with the temperature range corresponding to seasonal weather patterns. 

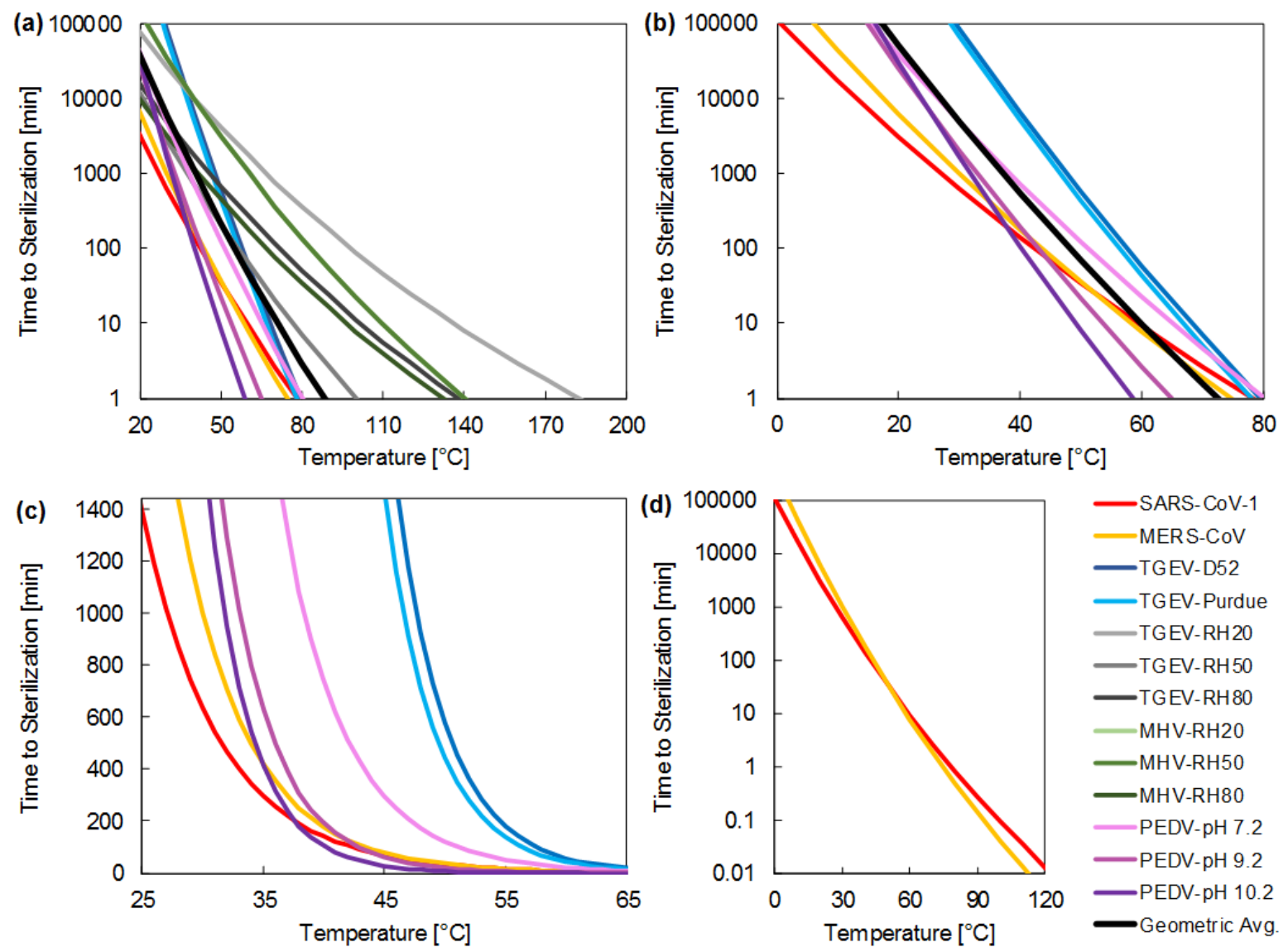

Figure 2. Model predictions of the time required for sterilization as a function of temperature for

166 (a) all data analyzed in this work and (b) all data excluding the data from Casanova, et al.,

167 where the average curves apply to the data shown in each panel. The subset of data in (b) is

168 replotted with a linearly-scaled vertical axis (1440 minutes $=1$ day) to highlight the exponential

169 dependence of sterilization time on temperature (c). The two human coronaviruses included in this work exhibit similar thermal degradation behavior and sterilization times (d). 
174 the subset of human coronaviruses (SARS-CoV-1 and MERS-CoV) analyzed in this work.

175

176

177

178

180

181

182

183

184

185

186

187 188 corresponding estimated inactivation time for SARS-CoV-1 and MERS-CoV (details in the Supporting

\begin{tabular}{c|c|c|c|c|} 
& $\begin{array}{c}\text { Maximum } \\
\text { coronavirus } \\
\text { sterilization } \\
\text { time, } \boldsymbol{t}_{\text {6-log }}\end{array}$ & $\begin{array}{c}\text { Average } \\
\text { coronavirus } \\
\text { sterilization } \\
\text { time, } \boldsymbol{t}_{\text {6-log }}\end{array}$ & $\begin{array}{c}\text { Max. human } \\
\text { coronavirus } \\
\text { sterilization } \\
\text { time, } \boldsymbol{t}_{\text {6-log }}\end{array}$ & $\begin{array}{c}\text { Avg. human } \\
\text { coronavirus } \\
\text { sterilization } \\
\text { time, } \boldsymbol{t}_{\text {-log }}\end{array}$ \\
\hline $60^{\circ} \mathrm{C}$ & $29 \mathrm{~h}$ & $48 \mathrm{~min}$ & $9 \mathrm{~min}$ & $8 \mathrm{~min}$ \\
$80^{\circ} \mathrm{C}$ & $6 \mathrm{~h}$ & $3 \mathrm{~min}$ & $<1 \mathrm{~min}$ & $<1 \mathrm{~min}$ \\
$100^{\circ} \mathrm{C}$ & $89 \mathrm{~min}$ & $<1 \mathrm{~min}$ & $<1 \mathrm{~min}$ & $<1 \mathrm{~min}$
\end{tabular}

Table 2. Time required for inactivation due to thermal denaturation of human coronaviruses outside of hosts across environmental temperatures ranging from $0{ }^{\circ} \mathrm{C}$ to $40^{\circ} \mathrm{C}$.

\begin{tabular}{c|c|c|} 
Temperature & $\begin{array}{c}\text { SARS-CoV-1 } \\
\text { inactivation } \\
\text { time, } \boldsymbol{t}_{\text {6-log }}\end{array}$ & $\begin{array}{c}\text { MERS-CoV9 } \\
\text { inactivation } \\
\text { time, } \boldsymbol{t}_{\text {6-log }}\end{array}$ \\
\hline $0^{\circ} \mathrm{C}$ & $>1$ month & $>1$ month \\
$5{ }^{\circ} \mathrm{C}$ & $30.1 \mathrm{~d}$ & $>1$ month \\
$10^{\circ} \mathrm{C}$ & $12.2 \mathrm{~d}$ & $31.1 \mathrm{~d}$ \\
$15^{\circ} \mathrm{C}$ & $5.1 \mathrm{~d}$ & $11.5 \mathrm{~d}$ \\
$20^{\circ} \mathrm{C}$ & $2.2 \mathrm{~d}$ & $4.3 \mathrm{~d}$ \\
$25^{\circ} \mathrm{C}$ & $23.3 \mathrm{~h}$ & $1.7 \mathrm{~d}$ \\
$30^{\circ} \mathrm{C}$ & $10.6 \mathrm{~h}$ & $16.7 \mathrm{~h}$ \\
$35^{\circ} \mathrm{C}$ & $4.9 \mathrm{~h}$ & $7.0 \mathrm{~h}$ \\
$40^{\circ} \mathrm{C}$ & $2.4 \mathrm{~h}$ & $3.0 \mathrm{~h}$
\end{tabular}

82 Depending on regional temperatures, coronavirus inactivation times may vary significantly. We estimated 83 the average time required for a 6-log reduction in concentration for SARS-CoV-1 and MERS-CoV, 84 corresponding to the effective lifetime of these viruses, based on regional temperatures in the United 85 States averaged over January to March, 2020, corresponding to the timeline of the COVID-19 pandemic 86 to date. Virus inactivation times were determined using Eq. 3 and the appropriate $E_{\mathrm{a}}$ and $\ln (A)$ data.

87 Figure 3 shows a map of the United States with regions of different average temperatures and the 
Information, Section S4). The predictions in Figure 3 are based on a simplified constant temporal

190 temperature profile and do not account for daily temperature fluctuations, which may result in even

191 shorter inactivation times than predicted due to the exponential dependence of reaction rate on

192 temperature. Additional environmental effects, like UV from sunlight, may further reduce inactivation

193 time; with these limitations in mind, predicted inactivation times longer than one month are not reported.
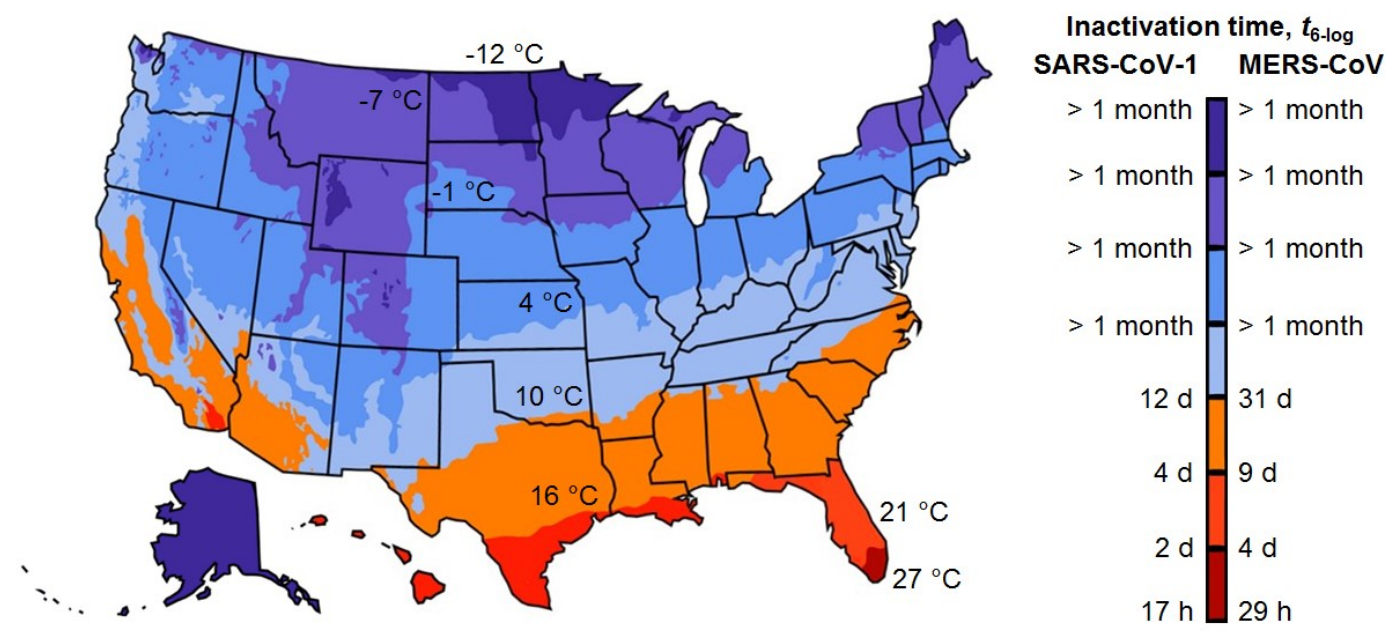

Figure 3. Predicted time required for inactivation of SARS-CoV-1 and MERS-CoV outside of a host across the United States based on average temperature data from January to March, 2020.

\section{DISCUSSION}

200 We compared results from the thermodynamic model presented here with experimental data that had not 201 been used as part of the model training data in order to test its predictive ability. SARS-CoV-1 has been 202 reported to require 22 days at $4{ }^{\circ} \mathrm{C}$ to achieve a 4-log reduction, and between $1-2$ days at $20{ }^{\circ} \mathrm{C}$ to achieve 203 a 5-log reduction; our model predicts times of 24 days and 1.8 days under the same conditions, 204 respectively, in good agreement with the reported data. ${ }^{41}$ In another report, SARS-CoV-1 was heated to $56{ }^{\circ} \mathrm{C}$ and required only 6 minutes to achieve a 6-log reduction; ${ }^{20}$ our model predicts a time of 15 minutes. A third report claimed that SARS-CoV-1 required 30 minutes to achieve an approximately 6$207 \log$ reduction at $60{ }^{\circ} \mathrm{C}$; our model predicts a time of 9 minutes. ${ }^{42}$ Finally, recent work showed that SARS- 
CoV-1 underwent a 2-to-3-log reduction over 8 to 24 hours at room temperature; ${ }^{17}$ our model predicts a timeframe of 18 to 26 hours. Considering the demonstrated similarity in inactivation behavior of SARSCoV-1 and SARS-CoV-2, ${ }^{17}$ as well as the similarity in our model predictions for different strains of other 211 coronaviruses (Figure S23), the model presented here will likely be a useful tool to estimate the 212 thermally-dependent inactivation behavior of SARS-CoV-2 based on predictions for SARS-CoV-1.

214 This model is limited to temperature-based predictive ability, and does not consider other environmental 215 variables like the relative humidity and the surface material on which a virion rests, both of which appear 216 to have an effect on inactivation times. ${ }^{11,17,43}$ Variations in inactivation time at a given temperature due to 217 these environmental factors may be interpreted as catalytic effects, ${ }^{44}$ where the activation energy is 218 lowered on solid surfaces, in the presence of water vapor, or even under different $\mathrm{pH}$ levels (effect shown 219 in Figure S26). Incorporating such an adjustment to the activation energy into the present model would 220 enable, in addition to temperature, predictive capability for other environmental conditions as well. 221 Another limitation of this model is its reliance on a limited set of primary data, which is taken under 222 different conditions and may also contain experimental error (all primary data is shown in the Supporting 223 Information). In addition, although most of the predictive capability of our model is applied within the 224 range of temperatures corresponding to the primary data, the ability of our model to extrapolate to higher 225 temperatures (e.g. above $100^{\circ} \mathrm{C}$ ) may be unfounded if new inactivation reaction pathways become 226 available at higher temperatures. Fortunately, the results in Table 1 indicate that dry heat sterilization is feasible for inactivation of coronaviruses. The most common material used in surgical masks and N95 respirators is non-woven 230 polypropylene. ${ }^{45,46}$ Polypropylene is mainly used in room temperature conditions, already well above its 231 glass transition temperature ${ }^{47,48}$ and within a region of near-constant stiffness until approaching its 232 melting point, which is typically within the range $156^{\circ} \mathrm{C}$ to $168{ }^{\circ} \mathrm{C} .{ }^{49,50} \mathrm{Cui}$ and colleagues suggest that 233 thermal cycling $\left(75^{\circ} \mathrm{C}, 30\right.$ min heating, applied over 20 cycles $)$ does not degrade the filtration efficiency 
234 of N95-level facial masks, ${ }^{7}$ and Lin et al. have shown that there is no significant degradation of surgical 235 masks after heating to $160{ }^{\circ} \mathrm{C}$ for $3 \mathrm{~min}^{5}$ Therefore, we expect that repeated sterilization at lower 236 temperatures will be effective without degrading masks, while also feasible within relatively short times

237 (less than $10 \mathrm{~min}$; Table 1) and achievable for the majority of humans with access to home ovens, rice 238 cookers, or similar inexpensive heating devices.

240 In summary, this work provides guidelines to the public for the effective, safe thermal sterilization of 241 medical PPE, including surgical masks, gowns, and face shields, and even the cloth masks - already 242 popular worldwide - that the CDC has recommended all US citizens wear during the COVID-19 243 pandemic, ${ }^{51}$ especially given the demonstrated similarity between the inactivation behavior SARS-CoV-1 244 and SARS-CoV-2. ${ }^{17}$ In addition, the sensitivity of coronaviruses to environmental temperature variations 245 shown in Table 2 and Figure 3 indicates that the thermal inactivation of SARS-CoV-2 must be considered in epidemiological studies predicting its global spread and, potentially, seasonal recurrence.

\section{ACKNOWLEDGEMENT}

249 We gratefully acknowledge helpful discussions with Dr. Dimithree Kahanda and financial support from 250 Rice University.

\section{AUTHOR CONTRIBUTIONS} T.F.Y. and D.J.P. compiled and analyzed the data and developed the analytical model. All authors 254 contributed to writing and editing the manuscript. D.J.P. guided the work.

\section{NOTES}

257 The authors declare no competing financial interest. 


\section{REFERENCES}

(1) Heimbuch, B. K.; Wallace, W. H.; Kinney, K.; Lumley, A. E.; Wu, C. Y.; Woo, M. H.; Wander, J. D. A Pandemic Influenza Preparedness Study: Use of Energetic Methods to Decontaminate Filtering Facepiece Respirators Contaminated with H1N1 Aerosols and Droplets. Am. J. Infect. Control 2011. https://doi.org/10.1016/j.ajic.2010.07.004.

(2) Viscusi, D. J.; King, W. P.; Shaffer, R. E. Effect of Decontamination on the Filtration Efficiency of Two Filtering Facepiece Respirator Models. J. Int. Soc. Respir. Prot. 2007.

(3) Kolata, G. As Coronavirus Looms, Mask Shortage Gives Rise to Promising Approach. The New York Times. 2020.

(4) Cramer, A.; Tian, E.; Yu, S. H.; Galanek, M.; Lamere, E.; Li, J.; Gupta, R.; Short, M. P. Disposable N95 Masks Pass Qualitative Fit-Test But Have Decreased Filtration Efficiency after Cobalt-60 Gamma Irradiation. medRxiv 2020. https://doi.org/10.1101/2020.03.28.20043471.

(5) Lin, T. H.; Tang, F. C.; Hung, P. C.; Hua, Z. C.; Lai, C. Y. Relative Survival of Bacillus Subtilis Spores Loaded on Filtering Facepiece Respirators after Five Decontamination Methods. Indoor Air 2018. https://doi.org/10.1111/ina.12475.

(6) Viscusi, D. J.; Bergman, M. S.; Eimer, B. C.; Shaffer, R. E. Evaluation of Five Decontamination Methods for Filtering Facepiece Respirators. Ann. Occup. Hyg. 2009. https://doi.org/10.1093/annhyg/mep070.

(7) Liao, D. L.; Xiao, W.; Yu, X.; Wang, H.; Zhao, D. M.; Wang, D. Q. Can N95 Facial Masks Be Used after Disinfection? And for How Many Times? Rep. from Collab. Stanford Univ. 4C Air, Inc 2020.

(8) Lowen, A. C.; Steel, J. Roles of Humidity and Temperature in Shaping Influenza Seasonality. $J$. Virol. 2014. https://doi.org/10.1128/jvi.03544-13.

(9) Petrova, V. N.; Russell, C. A. The Evolution of Seasonal Influenza Viruses. Nature Reviews Microbiology. 2018. https://doi.org/10.1038/nrmicro.2017.118.

(10) Ikäheimo, T. M.; Jaakkola, K.; Jokelainen, J.; Saukkoriipi, A.; Roivainen, M.; Juvonen, R.; 
Vainio, O.; Jaakkola, J. J. K. A Decrease in Temperature and Humidity Precedes Human Rhinovirus Infections in a Cold Climate. Viruses 2016. https://doi.org/10.3390/v8090244.

(11) Casanova, L. M.; Jeon, S.; Rutala, W. A.; Weber, D. J.; Sobsey, M. D. Effects of Air Temperature and Relative Humidity on Coronavirus Survival on Surfaces. Appl. Environ. Microbiol. 2010. https://doi.org/10.1128/AEM.02291-09.

(12) Lin, J.; Kang, M.; Zhong, H.; Zhang, X.; Yang, F.; Ni, H.; Huang, P.; Hong, T.; Ke, C.; He, J. Influenza Seasonality and Predominant Subtypes of Influenza Virus in Guangdong, China, 20042012. J. Thorac. Dis. 2013. https://doi.org/10.3978/j.issn.2072-1439.2013.08.09.

(13) Ellis, J. L.; Titone, J. C.; Tomasko, D. L.; Annabi, N.; Dehghani, F. Supercritical CO2 Sterilization of Ultra-High Molecular Weight Polyethylene. J. Supercrit. Fluids 2010. https://doi.org/10.1016/j.supflu.2010.01.002.

(14) Andersen, H. K.; Fiehn, N. E.; Larsen, T. Effect of Steam Sterilization inside the Turbine Chambers of Dental Turbines. Oral Surg. Oral Med. Oral Pathol. Oral Radiol. Endod. 1999. https://doi.org/10.1016/S1079-2104(99)70271-4.

(15) Mastanaiah, N.; Johnson, J. A.; Roy, S. Effect of Dielectric and Liquid on Plasma Sterilization Using Dielectric Barrier Discharge Plasma. PLoS One 2013. https://doi.org/10.1371/journal.pone.0070840.

(16) Rutala, W. A.; Weber, D. J. Low-Temperature Sterilization Technologies: Do We Need to Redefine “Sterilization”? Infect. Control Hosp. Epidemiol. 1996. https://doi.org/10.2307/30141007.

(17) van Doremalen, N.; Bushmaker, T.; Morris, D. H.; Holbrook, M. G.; Gamble, A.; Williamson, B. N.; Tamin, A.; Harcourt, J. L.; Thornburg, N. J.; Gerber, S. I.; Lloyd-Smith, J. O.; de Wit, E.; Munster, V. J. Aerosol and Surface Stability of SARS-CoV-2 as Compared with SARS-CoV-1. N. Engl. J. Med. 2020. https://doi.org/10.1056/nejmc2004973.

(18) Masters, P. S. The Molecular Biology of Coronaviruses. Advances in Virus Research. 2006. https://doi.org/10.1016/S0065-3527(06)66005-3. 
(19) Darnell, M. E. R.; Taylor, D. R. Evaluation of Inactivation Methods for Severe Acute Respiratory Syndrome Coronavirus in Noncellular Blood Products. Transfusion 2006. https://doi.org/10.1111/j.1537-2995.2006.00976.x.

(20) Kariwa, H.; Fujii, N.; Takashima, I. Inactivation of SARS Coronavirus by Means of PovidoneIodine, Physical Conditions and Chemical Reagents. In Dermatology; 2006. https://doi.org/10.1159/000089211.

(21) Rabenau, H. F.; Cinatl, J.; Morgenstern, B.; Bauer, G.; Preiser, W.; Doerr, H. W. Stability and Inactivation of SARS Coronavirus. Med. Microbiol. Immunol. 2005. https://doi.org/10.1007/s00430-004-0219-0.

(22) Leclercq, I.; Batéjat, C.; Burguière, A. M.; Manuguerra, J. C. Heat Inactivation of the Middle East Respiratory Syndrome Coronavirus. Influenza Other Respi. Viruses 2014. https://doi.org/10.1111/irv.12261.

(23) van Doremalen, N.; Bushmaker, T.; Munster, V. J. Stability of Middle East Respiratory Syndrome Coronavirus (MERS-CoV) under Different Environmental Conditions. Eurosurveillance 2013, 18 (38), 1-4. https://doi.org/10.2807/1560-7917.ES2013.18.38.20590.

(24) Laude, H. Thermal Inactivation Studies of a Coronavirus, Transmissible Gastroenteritis Virus. $J$. Gen. Virol. 1981. https://doi.org/10.1099/0022-1317-56-2-235.

(25) Lelie, P. N.; Reesink, H. W.; Lucas, C. J. Inactivation of 12 Viruses by Heating Steps Applied during Manufacture of a Hepatitis B Vaccine. J. Med. Virol. 1987. https://doi.org/10.1002/jmv.1890230313.

(26) Saknimit, M.; Inatsuki, I.; Sugiyama, Y.; Yagami, K. Virucidal Efficacy of Physico-Chemical Treatments against Coronaviruses and Parvoviruses of Laboratory Animals. Jikken Dobutsu. 1988. https://doi.org/10.1538/expanim1978.37.3_341.

(27) Quist-Rybachuk, G. V.; Nauwynck, H. J.; Kalmar, I. D. Sensitivity of Porcine Epidemic Diarrhea Virus (PEDV) to PH and Heat Treatment in the Presence or Absence of Porcine Plasma. Vet. Microbiol. 2015. https://doi.org/10.1016/j.vetmic.2015.10.010. 
(28) Xu, J.; Zhao, S.; Teng, T.; Abdalla, A. E.; Zhu, W.; Xie, L.; Wang, Y.; Guo, X. Systematic Comparison of Two Animal-to-Human Transmitted Human Coronaviruses: SARS-CoV-2 and SARS-CoV. Viruses 2020. https://doi.org/10.3390/v12020244.

(29) Possee, R. D. Baculovirus Expression Vectors — A Laboratory Manual. Trends Biotechnol. 1993. https://doi.org/10.1016/0167-7799(93)90146-z.

(30) Neill, K. O.; Huang, N.; Unis, D.; Clem, R. J. Rapid Selection against Arbovirus-Induced Apoptosis during Infection of a Mosquito Vector. Proc. Natl. Acad. Sci. U. S. A. 2015. https://doi.org/10.1073/pnas.1424469112.

(31) Li, S.; Zhao, H.; Yang, H.; Hou, W.; Cruz-Cosme, R.; Cao, R.; Chen, C.; Wang, W.; Xu, L.; Zhang, J.; Zhong, W.; Xia, N.; Tang, Q.; Cheng, T. Rapid Neutralization Testing System for Zika Virus Based on an Enzyme-Linked Immunospot Assay. ACS Infect. Dis. 2020. https://doi.org/10.1021/acsinfecdis.9b00333.

(32) Hulst, M. M.; Heres, L.; Hakze-van der Honing, R. W.; Pelser, M.; Fox, M.; van der Poel, W. H. M. Study on Inactivation of Porcine Epidemic Diarrhoea Virus, Porcine Sapelovirus 1 and Adenovirus in the Production and Storage of Laboratory Spray-Dried Porcine Plasma. J. Appl. Microbiol. 2019. https://doi.org/10.1111/jam.14235.

(33) C.R., S. Thermobacteriology in Food Processing (2nd Ed). New York Acad. Press 1973.

(34) Xiong, R.; Xie, G.; Edmondson, A. E.; Sheard, M. A. A Mathematical Model for Bacterial Inactivation. Int. J. Food Microbiol. 1999. https://doi.org/10.1016/S0168-1605(98)00172-X.

(35) CERF, O. A REVIEW Tailing of Survival Curves of Bacterial Spores. J. Appl. Bacteriol. 1977. https://doi.org/10.1111/j.1365-2672.1977.tb00665.x.

(36) Casolari, A. Microbial Death. In Physiological Models in Microbiology: Volume II; 2018. https://doi.org/10.1201/9781351075640.

(37) Van Boekel, M. A. J. S. On the Use of the Weibull Model to Describe Thermal Inactivation of Microbial Vegetative Cells. Int. J. Food Microbiol. 2002. https://doi.org/10.1016/S01681605(01)00742-5. 
(38) Price, W. C. Thermal Inactivation Rates of Four Plant Viruses. Arch. Gesamte Virusforsch. 1940. https://doi.org/10.1007/BF01245548.

(39) Qin, Z.; Balasubramanian, S. K.; Wolkers, W. F.; Pearce, J. A.; Bischof, J. C. Correlated Parameter Fit of Arrhenius Model for Thermal Denaturation of Proteins and Cells. Ann. Biomed. Eng. 2014. https://doi.org/10.1007/s10439-014-1100-y.

(40) Wright, N. T. On a Relationship between the Arrhenius Parameters from Thermal Damage Studies. J. Biomech. Eng. 2003. https://doi.org/10.1115/1.1553974.

(41) Lai, M. Y. Y.; Cheng, P. K. C.; Lim, W. W. L. Survival of Severe Acute Respiratory Syndrome Coronavirus. Clin. Infect. Dis. 2005. https://doi.org/10.1086/433186.

(42) Yunoki, M.; Urayama, T.; Yamamoto, I.; Abe, S.; Ikuta, K. Heat Sensitivity of a SARSAssociated Coronavirus Introduced into Plasma Products. Vox Sang. 2004. https://doi.org/10.1111/j.1423-0410.2004.00577.x.

(43) Chan, K. H.; Peiris, J. S. M.; Lam, S. Y.; Poon, L. L. M.; Yuen, K. Y.; Seto, W. H. The Effects of Temperature and Relative Humidity on the Viability of the SARS Coronavirus. Adv. Virol. 2011. https://doi.org/10.1155/2011/734690.

(44) Roduner, E. Understanding Catalysis. Chemical Society Reviews. 2014. https://doi.org/10.1039/c4cs00210e.

(45) Bałazy, A.; Toivola, M.; Adhikari, A.; Sivasubramani, S. K.; Reponen, T.; Grinshpun, S. A. Do N95 Respirators Provide 95\% Protection Level against Airborne Viruses, and How Adequate Are Surgical Masks? Am. J. Infect. Control 2006, 34 (2), 51-57. https://doi.org/10.1016/j.ajic.2005.08.018.

(46) Belkin, N. L. The Surgical Mask: Are New Tests Relevant for OR Practice? AORN J. 2009, 89 (5), 883-891. https://doi.org/10.1016/j.aorn.2008.09.016.

(47) Passaglia, E.; Martin, G. M. Variation of Glass Temperature with Pressure in Polypropylene. J. Res. Natl. Bur. Stand. Sect. A Phys. Chem. 1964, 68A (3), 273. https://doi.org/10.6028/jres.068a.024. 
(48) Bu, H.-S.; Cheng, S.; Wunderlich, B. Addendum to the Thermal Properties of Polypropylene. Die Makromol. Chemie, Rapid Commun. 1988, 9 (2), 75-77. https://doi.org/10.1002/marc.1988.030090205.

(49) Tiganis, B. E.; Shanks, R. A.; Long, Y. Effects of Processing on the Microstructure, Melting Behavior, and Equilibrium Melting Temperature of Polypropylene. J. Appl. Polym. Sci. 1996, 59 (4), 663-671. https://doi.org/10.1002/(sici)1097-4628(19960124)59:4<663::aid-app12>3.3.co;2-c.

(50) Duran, K.; Duran, D.; Oymak, G.; Kiliç, K.; Öncü, E.; Kara, M. Investigation of the Physical Properties of Meltblown Nonwovens for Air Filtration. Tekst. ve Konfeksiyon 2013, 23 (2), 136142.

(51) Michael D. Shear; Sheila Kaplan. A Debate Over Masks Uncovers Deep White House Divisions. The New York Times. 2002. 
403 A Predictive Model of the Temperature-Dependent Inactivation of Coronaviruses

404 Te Faye Yap, ${ }^{a}$ Zhen Liu, ${ }^{a, \dagger}$ Rachel A. Shveda, ${ }^{a, \dagger}$ Daniel J. Preston ${ }^{\mathrm{a}, *}$

405

$406{ }^{a}$ Department of Mechanical Engineering, Rice University, 6100 Main St., Houston, TX 77006

407

408 'Denotes equal contribution;

409 *To whom correspondence should be addressed: djp@rice.edu

411 Table of Contents

412 S1. Homogenization of Virus Inactivation Data

413 S2. Processing of Virus Inactivation Data

414 S3. Trends Across pH and Relative Humidity

415 S4. Conversion of Climate Data to Inactivation Timescale Map

\section{$\underline{\text { S1. Homogenization of Virus Inactivation Data }}$}

418 Data were obtained from the literature and homogenized according to the following procedures: (i) units

419 were converted to standard SI, except for the use of minutes in place of seconds following the convention

420 used in virology; (ii) $50 \%$ tissue culture infectious dose $\left(\mathrm{TCID}_{50}\right)$ assay results were converted to number

421 of plaque forming units (PFU) by multiplying by 0.69 based on theory, as performed in prior work; ${ }^{29-31}$

422 (iii) logarithms were all converted to base-e (the natural logarithm); (iv) data for which the experimental

423 error bars overlapped the lower detection limit (LDL) of the experimental technique were excluded

424 because they would artificially skew the resulting curve fits towards lower rate constants (i.e. slopes). 


\section{Data for SARS-CoV-1}

428 A $50 \%$ tissue culture infectious dose $\left(\mathrm{TCID}_{50}\right)$ assay was reported in the work by Darnell, et al. We 429 converted the $\mathrm{TCID}_{50}$ results to number of plaque forming units (PFU) by multiplying by 0.69 based on 430 theory, as performed in prior work, ${ }^{29-31}$ and then converted the data from $\log _{10}$ to the natural $\log$ before

431 plotting against time and taking a linear fit. Data near the lower detection limit (LDL) were excluded from 432 the analysis to avoid under-predicting the rate. In addition, data at $75{ }^{\circ} \mathrm{C}$ were excluded because only one 433 data point was not near the LDL, meaning a line could not be fit to the data. Linear fits for the data at 56 $434{ }^{\circ} \mathrm{C}$ and $65^{\circ} \mathrm{C}$ are presented in Figures $\mathbf{S 1}$ and $\mathbf{S 2}$. The resulting slopes were used to determine the rate 435 constants at these temperatures, reported in Table S1.

436

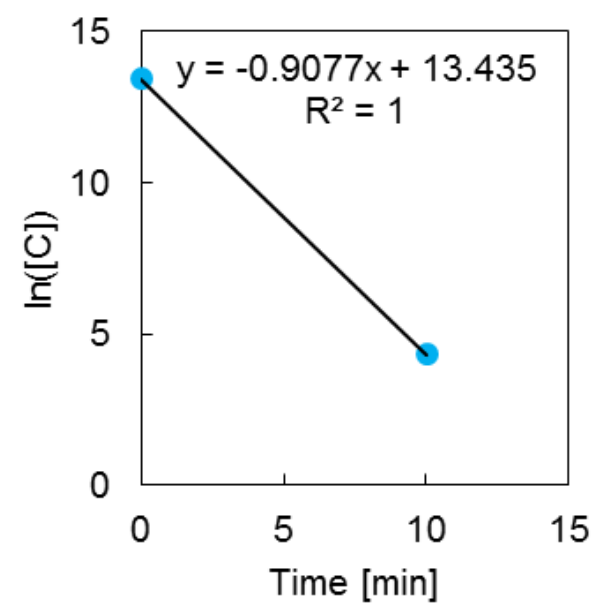

437

438 Figure S1. Primary data from Darnell, et al., ${ }^{19}$ for inactivation of SARS-CoV-1 at $56{ }^{\circ} \mathrm{C}$ after converting 439 the $y$-values from $\mathrm{TCID}_{50}$ to PFU and from $\log _{10}$ to the natural $\log$. We fit a line to the data to determine 440 the rate constant at $56^{\circ} \mathrm{C}$. 


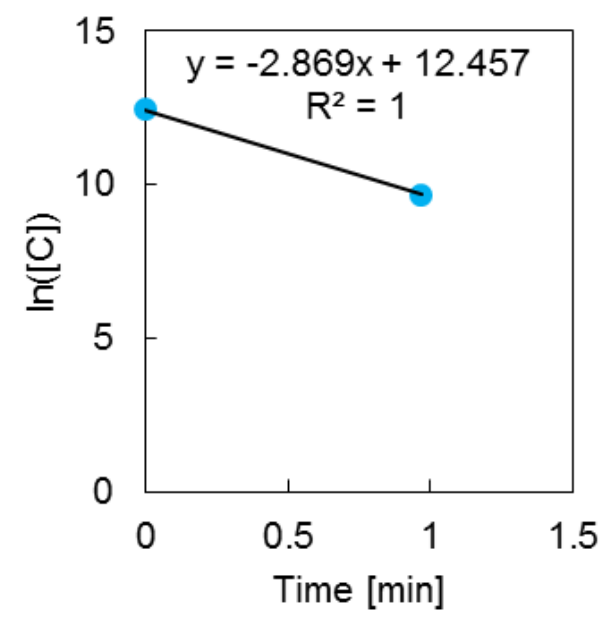

442

443 Figure S2. Primary data from Darnell, et al., ${ }^{19}$ for inactivation of SARS-CoV-1 at $65^{\circ} \mathrm{C}$ after converting 444 the y-values from $\mathrm{TCID}_{50}$ to PFU and from $\log _{10}$ to the natural $\log$. We fit a line to the data to determine 445 the rate constant at $65^{\circ} \mathrm{C}$.

\section{Data for MERS-CoV}

448 A $50 \%$ tissue culture infectious dose $\left(\mathrm{TCID}_{50}\right)$ assay was reported in the work by Leclerq, et al. A table 449 with information of the slopes (rate constant) at $56^{\circ} \mathrm{C}$ and $65^{\circ} \mathrm{C}$ was provided. We converted the value of 450 the slopes from $\log _{10}$ to the natural $\log$ and also the $\mathrm{TCID}_{50}$ results to number of plaque forming units 451 (PFU) by multiplying by 0.69 based on theory, as performed in prior work. ${ }^{29-31}$ Data at $25^{\circ} \mathrm{C}$ were 452 excluded due to the non-physical positive value for the slope (the concentration should decrease with 453 time), which was likely due to experimental error in the measurements eclipsing the small change in 454 concentration at $25^{\circ} \mathrm{C}$. The authors also mentioned in the paper that there was no decrease in titre after 2 455 hours for the data taken at $25^{\circ} \mathrm{C}$. The data for $20^{\circ} \mathrm{C}$ was obtained from work by Doremalen, et al. A $456 \mathrm{TCID}_{50}$ assay was reported in their work. We converted $\mathrm{TCID}_{50}$ results to number of plaque forming units 457 (PFU) by multiplying by 0.69 based on theory, as performed in prior work, ${ }^{29-31}$ and then converted the 458 data from $\log _{10}$ to the natural $\log$ before plotting against time and taking a linear fit. A linear fit for the 459 data at $20^{\circ} \mathrm{C}$ is presented in Figure $\mathbf{S 3}$ and the slope is computed to determine the rate constant at this 460 temperature, reported in Table S1. 


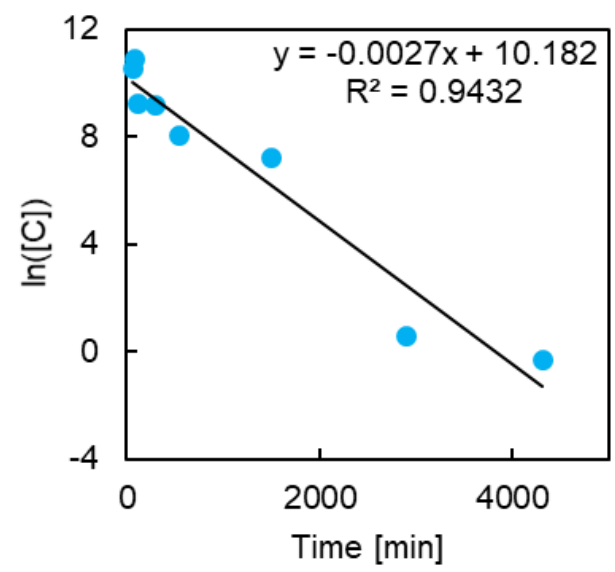

461

462 Figure S3. Primary data from Doremalen, et al., ${ }^{23}$ for inactivation of MERS-CoV at $20^{\circ} \mathrm{C}$ after

463 converting the $y$-values from $\mathrm{TCID}_{50}$ to $\mathrm{PFU}$ and from $\log _{10}$ to the natural $\log$. We fit a line to the data to 464 determine the rate constant at $20^{\circ} \mathrm{C}$.

Data for TGEV-D52 and TGEV-Purdue

An Arrhenius plot for thermal inactivation of TGEV D52 strain and Purdue strain was reported in the work by Laude, et al. The logarithms of the rate constants were provided for temperatures of 31, 35, 39, $43,47,51$, and $55^{\circ} \mathrm{C}$. We converted the value of the rate constants from $\log _{10}$ to the natural $\log$ and also converted the units from inverse seconds to inverse minutes to maintain consistency with the other data values used in this work. The converted rate constants are reported in Table S1.

\section{Data for TGEV at relative humidity (RH) values of 20\%, 50\%, and $80 \%$}

474 The virus concentration versus time for relative humidity $(\mathrm{RH})$ values of $20 \%, 50 \%$, and $80 \%$ at

475 temperatures of 4,20 , and $40^{\circ} \mathrm{C}$ was reported in the work by Casanova, et al. ${ }^{11}$ We converted the value of 476 the slopes from $\log _{10}$ to the natural $\log$ before plotting against time and taking the linear fit to find the rate 477 constant. Data near the lower detection limit (LDL) were excluded from the analysis to avoid under-

478 predicting the rate (because the slope of the linear fit would artificially become shallower due to the 479 inability to resolve lower concentrations experimentally). Linear fits for the data at 4,20 , and $40{ }^{\circ} \mathrm{C}$ and 
480 at relative humidity values of $20 \%, 50 \%$, and $80 \%$, respectively, are shown in Figures S4 to S12. The

481 resulting slopes were used to determine the rate constants at these temperatures, reported in Table S1.

482

483

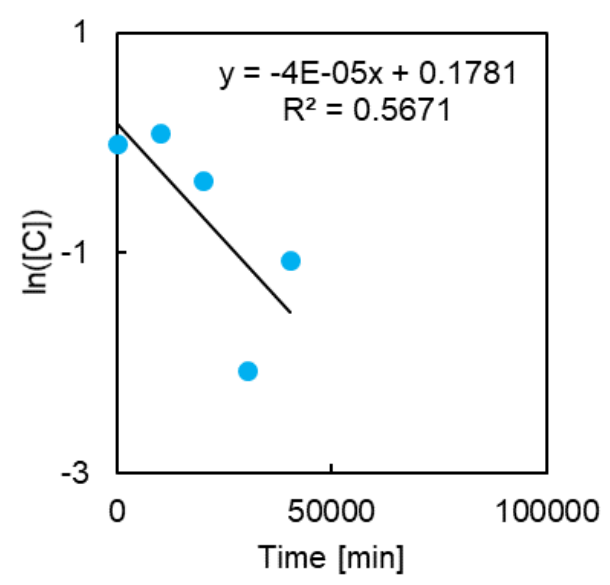

484 Figure S4. Primary data from Casanova et al., ${ }^{11}$ for inactivation of TGEV at $4{ }^{\circ} \mathrm{C}$ and relative humidity of $48520 \%$ after converting the $y$-values from $\log _{10}$ to the natural $\log$. We fit a line to the data to determine the 486 rate constant at $4{ }^{\circ} \mathrm{C}$ and $\mathrm{RH}$ of $20 \%$.

487

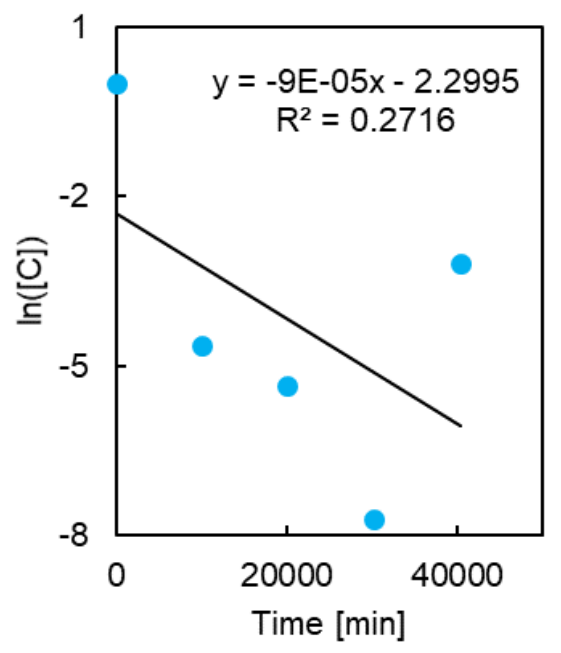

489 Figure S5. Primary data from Casanova et al., ${ }^{11}$ for inactivation of TGEV at $4{ }^{\circ} \mathrm{C}$ and relative humidity of $49050 \%$ after converting values from $\log _{10}$ to the natural $\log$. We fit a line to the data to determine the rate 491 constant at $4{ }^{\circ} \mathrm{C}$ and $\mathrm{RH}$ of $50 \%$. 


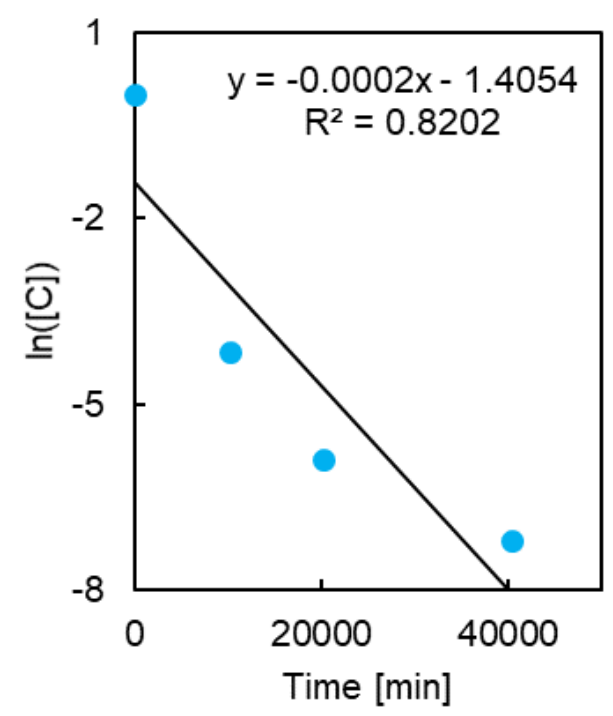

492

493 Figure S6. Primary data from Casanova et al., ${ }^{11}$ for inactivation of TGEV at $4{ }^{\circ} \mathrm{C}$ and relative humidity of $49480 \%$ after converting values from $\log _{10}$ to the natural $\log$. We fit a line to the data to determine the rate 495 constant at $4{ }^{\circ} \mathrm{C}$ and $\mathrm{RH}$ of $80 \%$.

496

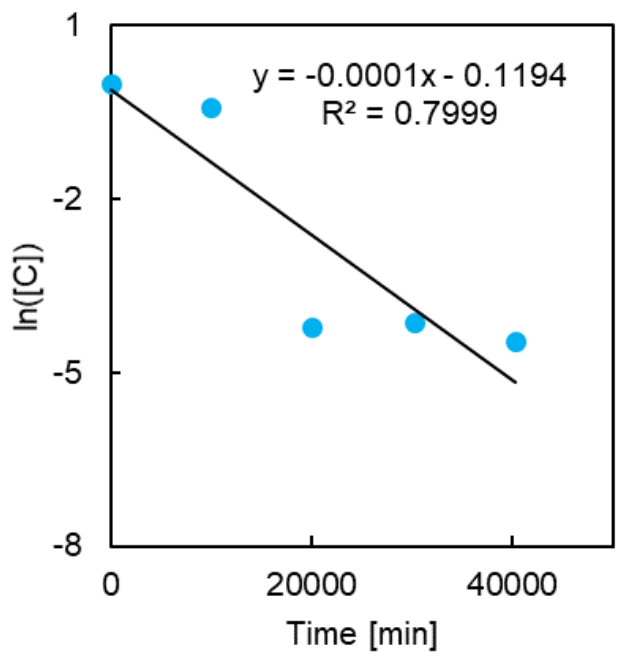

498 Figure S7. Primary data from Casanova et al., ${ }^{11}$ for inactivation of TGEV at $20{ }^{\circ} \mathrm{C}$ and relative humidity 499 of $20 \%$ after converting values from $\log _{10}$ to the natural $\log$. We fit a line to the data to determine the rate 500 constant at $20^{\circ} \mathrm{C}$ and $\mathrm{RH}$ of $20 \%$. 


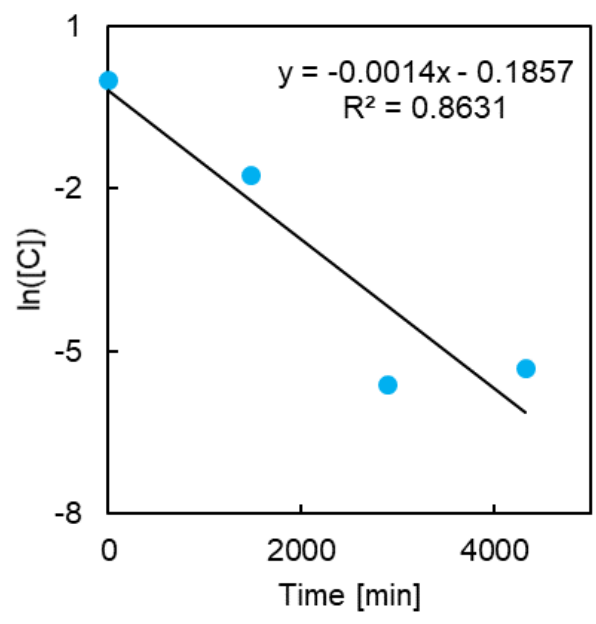

501

502 Figure S8. Primary data from Casanova et al., ${ }^{11}$ for inactivation of TGEV at $20{ }^{\circ} \mathrm{C}$ and relative humidity 503 of $50 \%$ after converting values from $\log _{10}$ to the natural $\log$. We fit a line to the data to determine the rate 504 constant at $20^{\circ} \mathrm{C}$ and $\mathrm{RH}$ of $50 \%$.

505

506

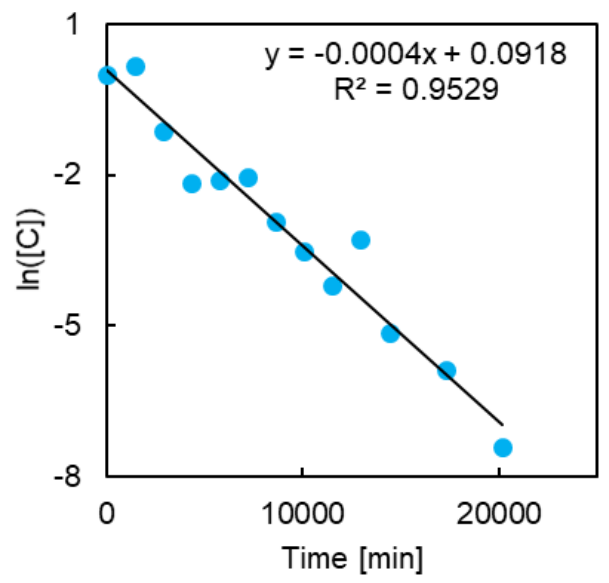

507

508 Figure S9. Primary data from Casanova et al., ${ }^{11}$ for inactivation of TGEV at $20{ }^{\circ} \mathrm{C}$ and relative humidity

509 of $80 \%$ after converting values from $\log _{10}$ to the natural $\log$. We fit a line to the data to determine the rate constant at $20{ }^{\circ} \mathrm{C}$ and $\mathrm{RH}$ of $80 \%$. 


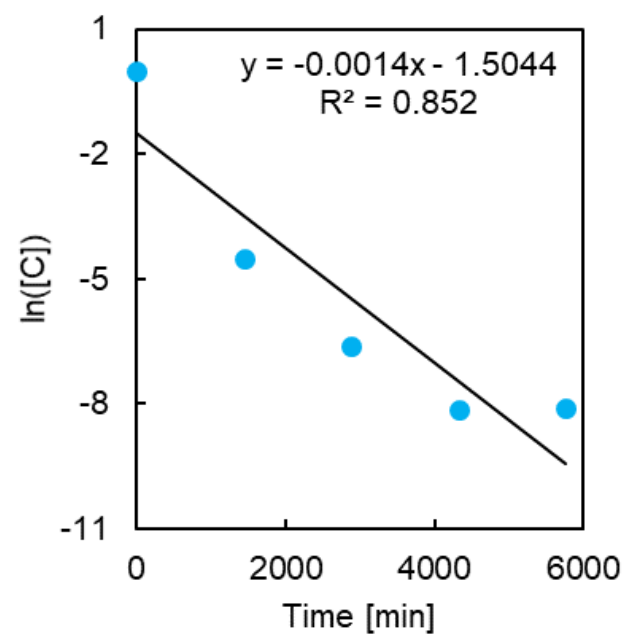

512

513 Figure S10. Primary data from Casanova et al., ${ }^{11}$ for inactivation of TGEV at $40{ }^{\circ} \mathrm{C}$ and relative humidity 514 of $20 \%$ after converting values from $\log _{10}$ to the natural $\log$. We fit a line to the data to determine the rate 515 constant at $40{ }^{\circ} \mathrm{C}$ and $\mathrm{RH}$ of $20 \%$.

516

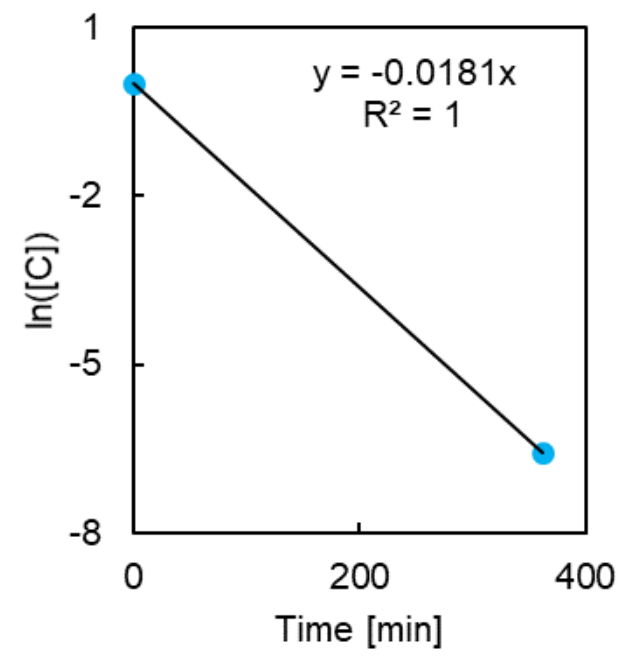

517

518 Figure S11. Primary data from Casanova et al., ${ }^{11}$ for inactivation of TGEV at $40{ }^{\circ} \mathrm{C}$ and relative humidity 519 of $50 \%$ after converting values from $\log _{10}$ to the natural $\log$. We fit a line to the data to determine the rate constant at $40{ }^{\circ} \mathrm{C}$ and $\mathrm{RH}$ of $50 \%$. 


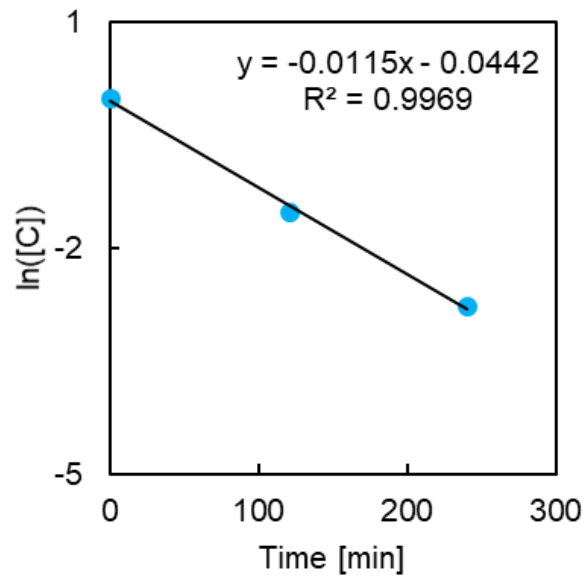

521

522 Figure S12. Primary data from Casanova et al., ${ }^{11}$ for inactivation of TGEV at $40{ }^{\circ} \mathrm{C}$ and relative humidity 523 of $80 \%$ after converting values from $\log _{10}$ to the natural $\log$. We fit a line to the data to determine the rate 524 constant at $40{ }^{\circ} \mathrm{C}$ and $\mathrm{RH}$ of $80 \%$.

Data for MHV at relative humidity (RH) values of $20 \%, 50 \%$, and $80 \%$

527 The virus concentration versus time for relative humidity $(\mathrm{RH})$ values of $20 \%, 50 \%$, and $80 \%$ at

528 temperatures of 4,20 , and $40^{\circ} \mathrm{C}$ was reported in the work by Casanova, et al. ${ }^{11}$ We converted the value of 529 the slopes from $\log _{10}$ to the natural $\log$ before plotting against time and taking the linear fit to find the rate 530 constant. Data near the lower detection limit (LDL) were excluded from the analysis to avoid under531 predicting the rate (because the slope of the linear fit would artificially become shallower due to the 532 inability to resolve lower concentrations experimentally). Linear fits for the data at 4,20 , and $40^{\circ} \mathrm{C}$ and at 533 relative humidity values of 20\%, 50\%, and 80\%, respectively, are shown in Figures S13 to S21. The 534 resulting slopes were used to determine the rate constants at these temperatures, reported in Table S1. 


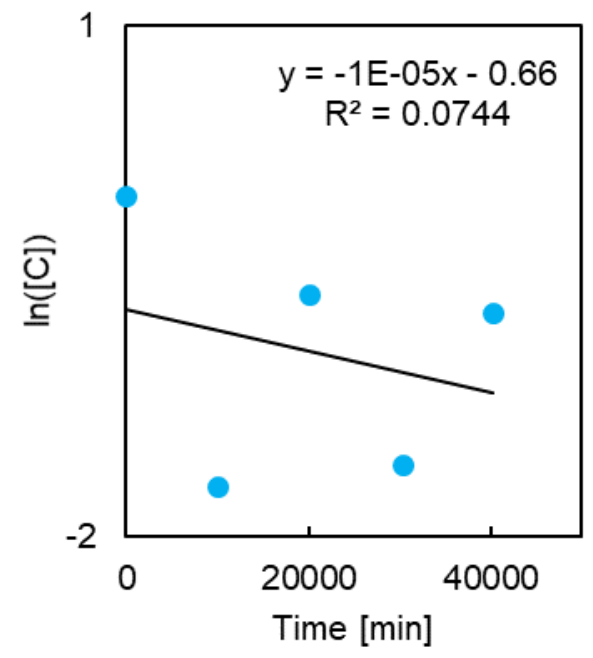

536

537 Figure S13. Primary data from Casanova et al., ${ }^{11}$ for inactivation of MHV at $4{ }^{\circ} \mathrm{C}$ and relative humidity 538 of $20 \%$ after converting values from $\log _{10}$ to the natural $\log$. We fit a line to the data to determine the rate 539 constant at $4{ }^{\circ} \mathrm{C}$ and $\mathrm{RH}$ of $20 \%$.

540

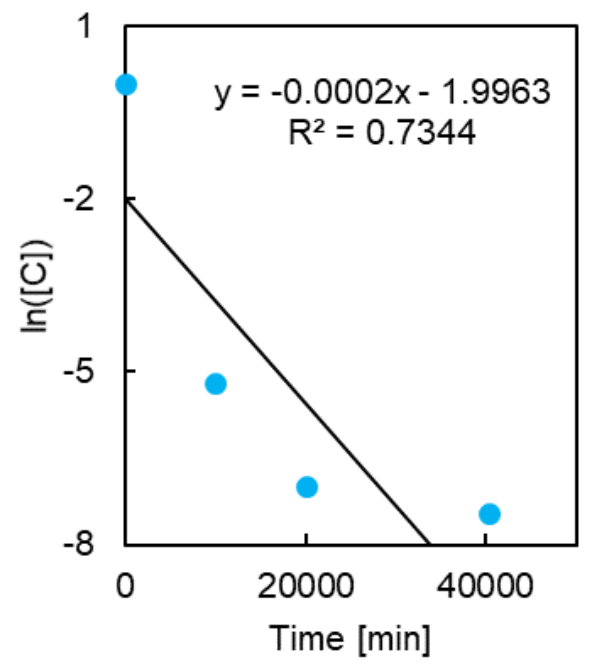

541

542 Figure S14. Primary data from Casanova et al., ${ }^{11}$ for inactivation of MHV at $4{ }^{\circ} \mathrm{C}$ and relative humidity 543 of $50 \%$ after converting values from $\log _{10}$ to the natural $\log$. We fit a line to the data to determine the rate 544 constant at $4{ }^{\circ} \mathrm{C}$ and $\mathrm{RH}$ of $50 \%$. 


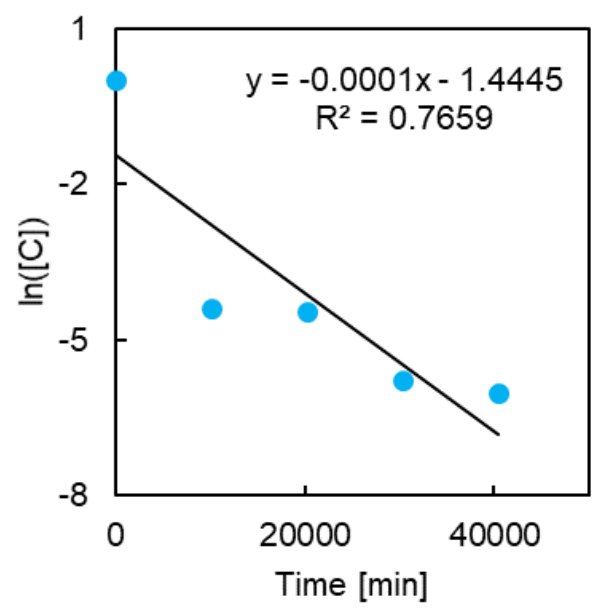

546

547 Figure S15. Primary data from Casanova et al., ${ }^{11}$ for inactivation of MHV at $4{ }^{\circ} \mathrm{C}$ and relative humidity 548 of $80 \%$ after converting values from $\log _{10}$ to the natural $\log$. We fit a line to the data to determine the rate 549 constant at $4{ }^{\circ} \mathrm{C}$ and $\mathrm{RH}$ of $80 \%$.

550

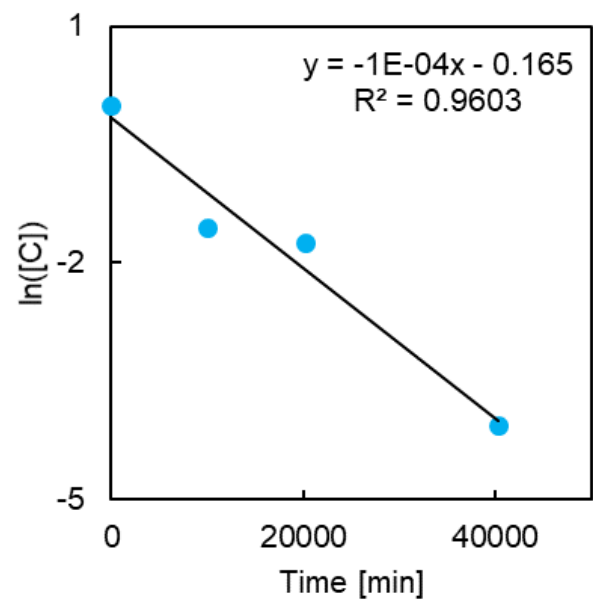

552 Figure S16. Primary data from Casanova et al., ${ }^{11}$ for inactivation of MHV at $20{ }^{\circ} \mathrm{C}$ and relative humidity 553 of $20 \%$ after converting values from $\log _{10}$ to the natural $\log$. We fit a line to the data to determine the rate 554 constant at $20^{\circ} \mathrm{C}$ and $\mathrm{RH}$ of $20 \%$. 


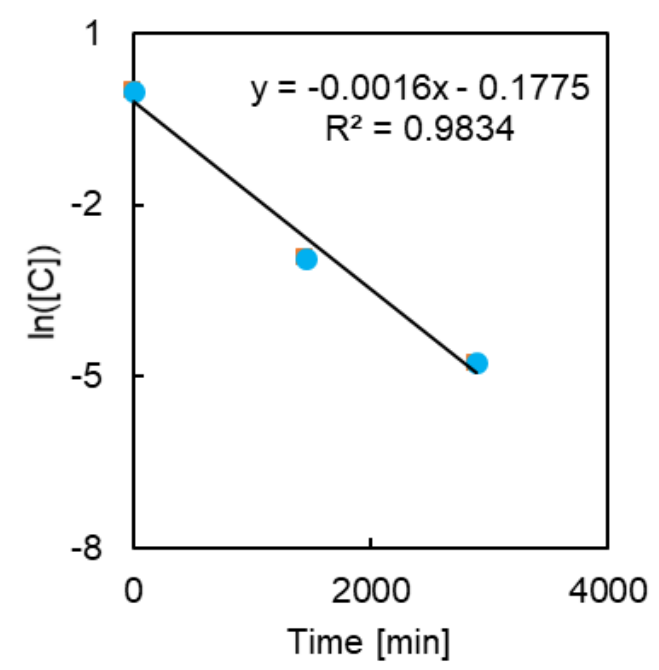

556

557 Figure S17. Primary data from Casanova et al., ${ }^{11}$ for inactivation of $\mathrm{MHV}$ at $20{ }^{\circ} \mathrm{C}$ and relative humidity 558 of $50 \%$ after converting values from $\log _{10}$ to the natural $\log$. We fit a line to the data to determine the rate 559 constant at $20^{\circ} \mathrm{C}$ and $\mathrm{RH}$ of $50 \%$.

560

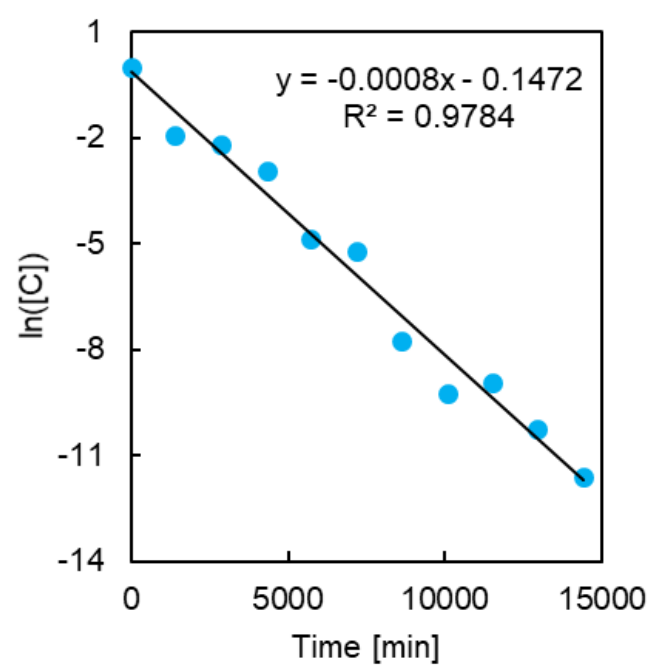

562 Figure S18. Primary data from Casanova et al., ${ }^{11}$ for inactivation of MHV at $20{ }^{\circ} \mathrm{C}$ and relative humidity 563 of $80 \%$ after converting values from $\log _{10}$ to the natural $\log$. We fit a line to the data to determine the rate 564 constant at $20{ }^{\circ} \mathrm{C}$ and $\mathrm{RH}$ of $80 \%$. 


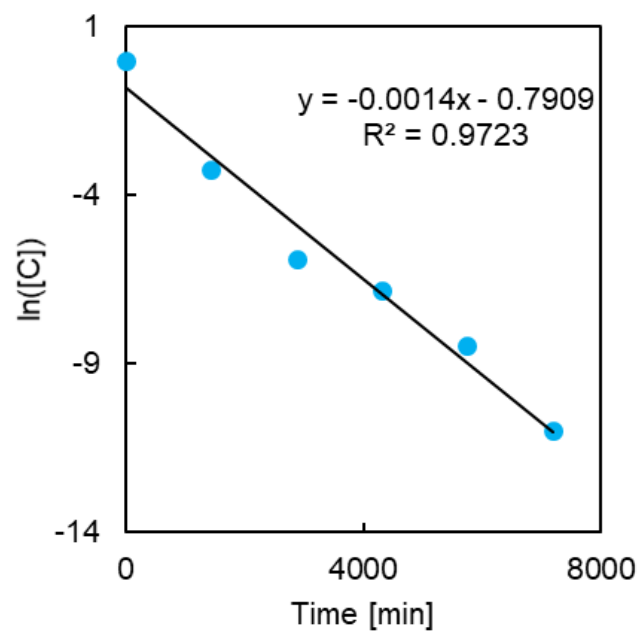

566

567 Figure S19. Primary data from Casanova et al., ${ }^{11}$ for inactivation of MHV at $40{ }^{\circ} \mathrm{C}$ and relative humidity

568 of $20 \%$ after converting values from $\log _{10}$ to the natural $\log$. We fit a line to the data to determine the rate

569 constant at $40{ }^{\circ} \mathrm{C}$ and $\mathrm{RH}$ of $20 \%$.

570

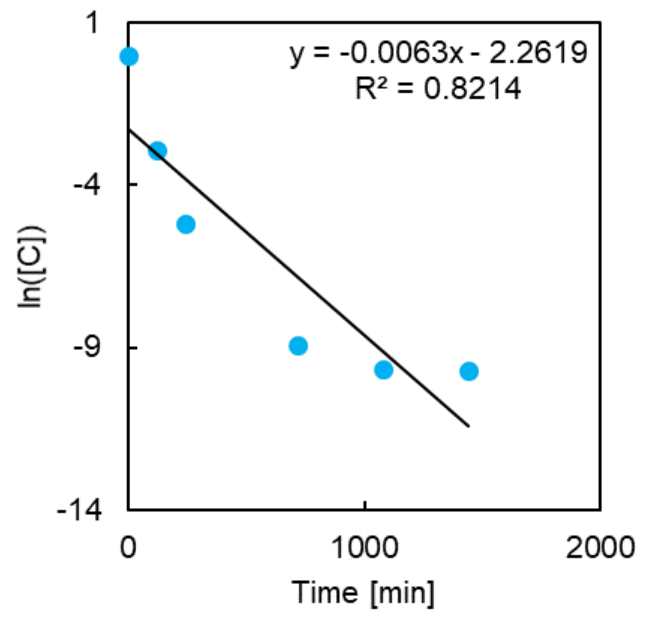

571

572 Figure S20. Primary data from Casanova et al., ${ }^{11}$ for inactivation of MHV at $40{ }^{\circ} \mathrm{C}$ and relative humidity 573 of $50 \%$ after converting values from $\log _{10}$ to the natural $\log$. We fit a line to the data to determine the rate 574 constant at $40{ }^{\circ} \mathrm{C}$ and $\mathrm{RH}$ of $50 \%$. 


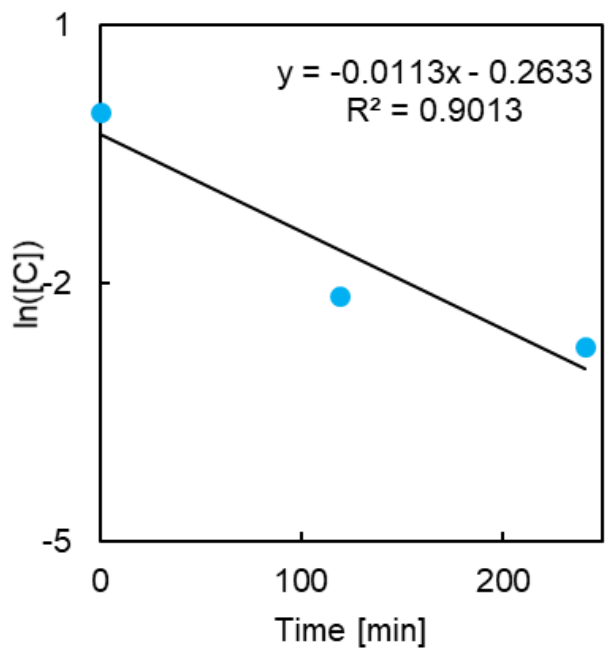

577 Figure S21. Primary data from Casanova et al., ${ }^{11}$ for inactivation of MHV at $40{ }^{\circ} \mathrm{C}$ and relative humidity 578 of $80 \%$ after converting values from $\log _{10}$ to the natural $\log$. We fit a line to the data to determine the rate 579 constant at $40{ }^{\circ} \mathrm{C}$ and $\mathrm{RH}$ of $80 \%$.

582 A 50\% tissue culture infectious dose $\left(\mathrm{TCID}_{50}\right)$ assay was reported in the work by Quist-Rybachuk, et al.

583 We converted TCID $_{50}$ results to number of plaque forming units (PFU) by multiplying by 0.69 based on 584 theory, as performed in prior work, ${ }^{29-31}$ and then converted the data from $\log _{10}$ to the natural $\log$ before 585 calculating the slope based on the best fit lines that the authors provided in their plots. Data near the lower 586 detection limit (LDL) had already been excluded from the authors' own analysis to avoid under-

587 predicting the rate. The calculated slopes were used to determine the rate constants at 40,44 , and $48{ }^{\circ} \mathrm{C}$ 588 for $\mathrm{pH}$ values of 7.2, 9.2, and 10.2, reported in Table S1. 


\section{$\underline{\text { S2. Processing of Virus Inactivation Data }}$}

591 This section contains all of the raw values for the processed data included in Figure 1. The data points in

592 Figure 1(a) are listed in Table S1, where the $\ln (k)$ values were calculated from the $k=-\mathrm{d}(\ln ([C])) / \mathrm{d} t$

593 values determined in Section S1, unless otherwise noted in the table. The slope-intercept data for all of

594 the linear fits in Figure 1 are listed in Table S2 and shown in Figure S22, along with the calculated 595 activation energy and frequency factor shown in Figure 1(b).

597 Table S1. Data plotted in Figure 1(a) in the main text.

\begin{tabular}{l|c|c|c|c} 
Dataset & $\boldsymbol{T}\left[{ }^{\circ} \mathbf{C}\right]$ & $\mathbf{1} / \mathbf{T} \cdot \mathbf{1 0}^{\mathbf{4}}\left[\mathbf{1 0} \mathbf{4}^{\mathbf{4}} \mathbf{K}\right]$ & $\boldsymbol{k}=-\mathbf{d}(\mathbf{l n}([\boldsymbol{C}])) / \mathbf{d} \boldsymbol{t}[\mathbf{1} / \mathbf{m i n}]$ & $\mathbf{l n}(\boldsymbol{k})[\mathbf{1} / \mathbf{m i n}]$ \\
\hline SARS-CoV-1 & 56 & 30.40 & 0.9077 & -0.0968 \\
\hline SARS-CoV-1 & 65 & 29.59 & 2.869 & 1.054 \\
\hline MERS-CoV & 20 & 34.13 & 0.0027 & -5.9145 \\
\hline MERS-CoV & 56 & 30.40 & 0.16 & -0.9985 \\
\hline MERS-CoV & 65 & 29.59 & 3.62 & 2.1211 \\
\hline TGEV-D52 & 31 & 32.90 & $\ln (k)$ provided in source & -7.963 \\
\hline TGEV-D52 & 35 & 32.47 & $\ln (k)$ provided in source & -7.332 \\
\hline TGEV-D52 & 39 & 32.05 & $\ln (k)$ provided in source & -6.439 \\
\hline TGEV-D52 & 43 & 31.65 & $\ln (k)$ provided in source & -5.808 \\
\hline TGEV-D52 & 47 & 31.25 & $\ln (k)$ provided in source & -4.837 \\
\hline TGEV-D52 & 51 & 30.86 & $\ln (k)$ provided in source & -3.369 \\
\hline TGEV-D52 & 55 & 30.48 & $\ln (k)$ provided in source & -1.823 \\
\hline TGEV-Purdue & 31 & 32.90 & $\ln (k)$ provided in source & -7.832 \\
\hline TGEV-Purdue & 35 & 32.47 & $\ln (k)$ provided in source & -7.149 \\
\hline TGEV-Purdue & 39 & 32.05 & $\ln (k)$ provided in source & -6.177 \\
\hline TGEV-Purdue & 43 & 31.65 & $\ln (k)$ provided in source & -5.468 \\
\hline TGEV-Purdue & 47 & 31.25 & $\ln (k)$ provided in source & -4.418 \\
\hline TGEV-Purdue & 55 & 30.48 & $\ln (k)$ provided in source & -1.849 \\
\hline TGEV-RH20 & 4 & 36.10 & 0.000042 & -10.126 \\
\hline TGEV-RH20 & 20 & 34.13 & 0.00013 & -9.21 \\
\hline TGEV-RH20 & 40 & 31.95 & 0.0014 & -6.57 \\
\hline & & & & \\
\hline
\end{tabular}




\begin{tabular}{|c|c|c|c|c|}
\hline TGEV-RH50 & 4 & 36.10 & 0.000093 & -9.316 \\
\hline TGEV-RH50 & 20 & 34.13 & 0.0014 & -6.571 \\
\hline TGEV-RH50 & 40 & 31.95 & 0.0181 & -4.012 \\
\hline TGEV-RH80 & 4 & 36.10 & 0.00017 & -8.517 \\
\hline TGEV-RH80 & 20 & 34.13 & 0.00035 & -7.824 \\
\hline TGEV-RH80 & 40 & 31.95 & 0.0115 & -4.465 \\
\hline MHV-RH20 & 4 & 36.10 & 0.000012 & -11.513 \\
\hline MHV-RH20 & 20 & 34.13 & 0.000095 & -9.210 \\
\hline MHV-RH20 & 40 & 31.95 & 0.0018 & -6.571 \\
\hline MHV-RH50 & 4 & 36.10 & 0.00017 & -8.517 \\
\hline MHV-RH50 & 20 & 34.13 & 0.0016 & -6.438 \\
\hline MHV-RH50 & 40 & 31.95 & 0.0114 & -4.474 \\
\hline MHV-RH80 & 4 & 36.10 & 0.00013 & -9.210 \\
\hline MHV-RH80 & 20 & 34.13 & 0.00080 & -7.131 \\
\hline MHV-RH80 & 40 & 31.95 & 0.0113 & -4.483 \\
\hline PEDV-pH 7.2 & 40 & 31.95 & 0.0211 & -3.858 \\
\hline PEDV-pH 7.2 & 44 & 31.55 & 0.0326 & -3.422 \\
\hline PEDV-pH 7.2 & 48 & 31.15 & 0.0900 & -2.407 \\
\hline PEDV-pH 9.2 & 40 & 31.95 & 0.0863 & -2.449 \\
\hline PEDV-pH 9.2 & 44 & 31.55 & 0.1295 & -2.044 \\
\hline PEDV-pH 9.2 & 48 & 31.15 & 0.5178 & -0.658 \\
\hline PEDV-pH 10.2 & 40 & 31.95 & 0.1618 & -1.821 \\
\hline PEDV-pH 10.2 & 44 & 31.55 & 0.2728 & -1.299 \\
\hline PEDV-pH 10.2 & 48 & 31.15 & 1.2943 & 0.258 \\
\hline
\end{tabular}

Table S2. Slopes and intercepts of data plotted in Figure 1(a) in the main text, and the calculated $\ln (A)$

600 and $E_{\mathrm{a}}$ values shown in Figure 1(b).

\begin{tabular}{l|c|c|c|c} 
Dataset & Slope $\left[\mathbf{K} / \mathbf{1 0}{ }^{\mathbf{4}}\right]$ & Intercept $[\mathbf{1} / \mathbf{m i n}]$ & $\boldsymbol{E}_{\mathbf{a}}[\mathbf{J} / \mathbf{m o l}]$ & $\ln (\boldsymbol{A})[\mathbf{1} / \mathbf{m i n}]$ \\
\hline SARS-CoV-1 & -1.4219 & 43.122 & 118223.876 & 43.122 \\
\hline MERS-CoV & -1.6282 & 49.48 & 135376.689 & 49.48 \\
\hline TGEV-D52 & -2.4514 & 72.205 & 203821.653 & 72.205 \\
\hline TGEV-Purdue & -2.4717 & 73.094 & 205509.497 & 73.094
\end{tabular}




\begin{tabular}{l|c|c|c|c} 
TGEV-RH20 & -0.924 & 22.919 & 76825.98 & 22.919 \\
\hline TGEV-RH50 & -1.2755 & 36.811 & 106051.448 & 36.811 \\
\hline TGEV-RH80 & -0.9858 & 26.64 & 81964.341 & 26.64 \\
\hline MHV-RH20 & -1.1905 & 31.449 & 98984.1225 & 31.449 \\
\hline MHV-RH50 & -0.9724 & 26.644 & 80850.198 & 26.644 \\
\hline MHV-RH80 & -1.1399 & 31.882 & 94776.9855 & 31.882 \\
\hline PEDV-pH7.2 & -1.8196 & 54.177 & 151290.642 & 54.177 \\
\hline PEDV-pH9.2 & -2.245 & 69.111 & 186660.525 & 69.111 \\
\hline PEDV-pH10.2 & -2.606 & 81.262 & 216675.87 & 81.262 \\
\hline
\end{tabular}

601

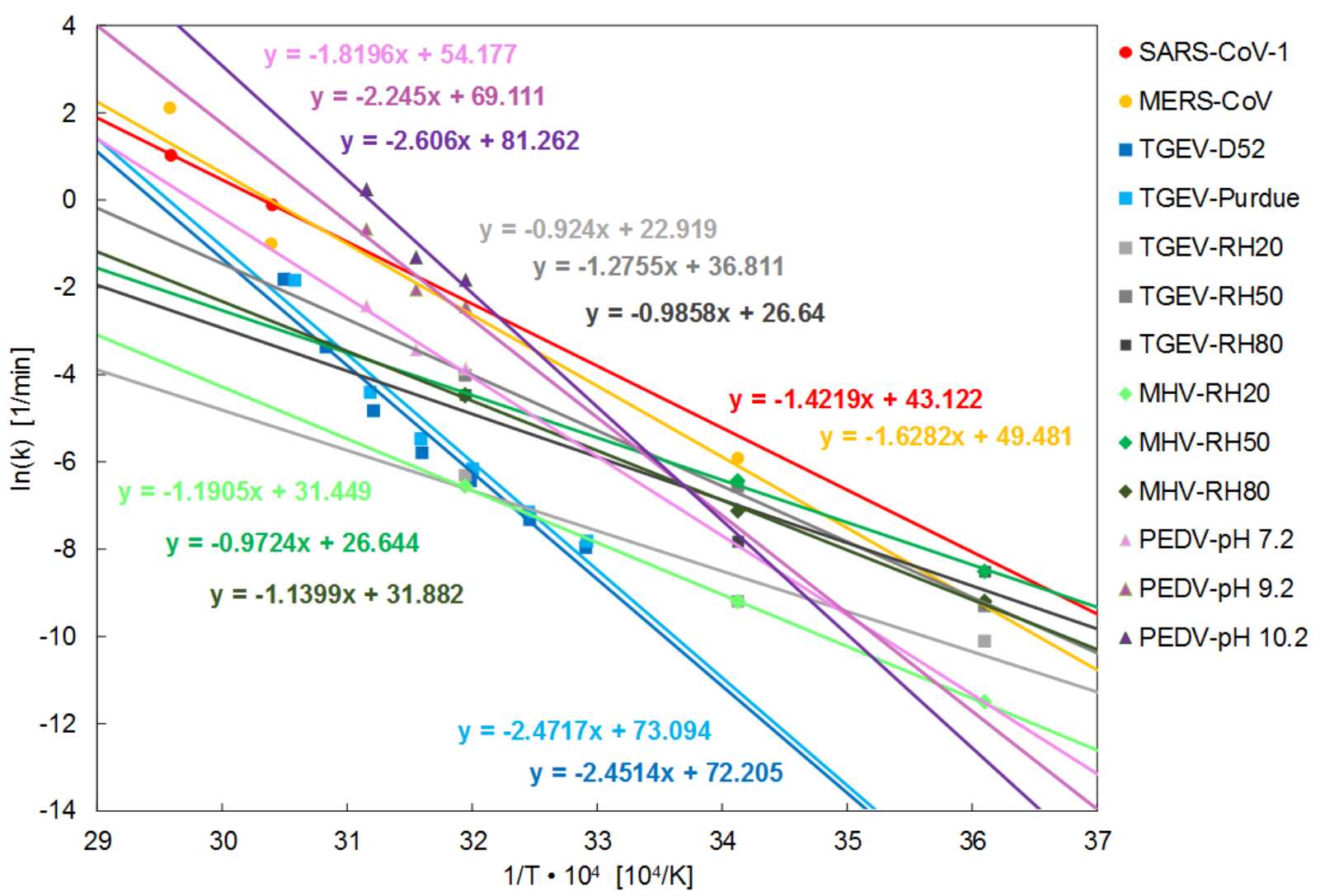

602

603 Figure S22. A magnified version of Figure 1(a) from the main text, with the slopes and intercepts for 604 each linear fit indicated.

605 
607 Subsets of the model predictions for several viruses that varied only by strain, relative humidity, or $\mathrm{pH}$ of 608 the surrounding medium are plotted here to more clearly highlight trends.

609

$610 \quad$ Trends across virus strains

611 Comparing results for the TGEV-D52 and TGEV-Purdue strains, we did not observe any significant

612 deviation in the model prediction between these strains, shown in Figure S23. We hypothesize that the

613 similarity between these two strains may be indicative of a similarity that SARS-CoV-2 could exhibit

614 with SARS-CoV-1; we have predictive capability for SARS-CoV-1 with the present model and data, and

615 the predictions for SARS-CoV-1 may suggest the expected thermal degradation of SARS-CoV-2.

616

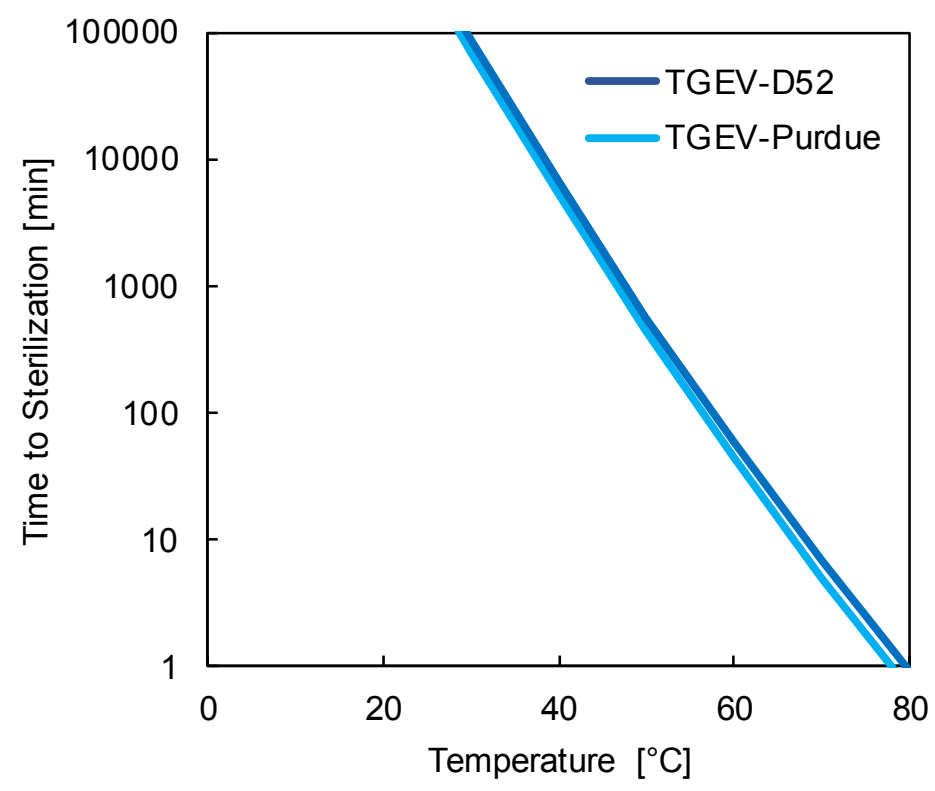

618 Figure S23. Model predictions for sterilization times required for the TGEV D52 and Purdue strains.

\section{Trends across relative humidity conditions}

621 Comparing results for the TGEV and MHV viruses at relative humidity levels of $20 \%, 50 \%$, and $80 \%$, we 622 did not observe any clear trends, as shown in Figures S24 and S25. We note that the dataset obtained 
623 from Casanova, et al., appeared to exhibit the most experimental error of all the data used in the model,

624 especially at low temperatures, with $\mathrm{R}^{2}$ values as low as 0.1 when applying linear fits to several sets of

625 their data in Section S1. Therefore, more data would be needed to rule out a correlation between virus

626 inactivation and relative humidity, especially considering such a trend has been implied in prior work. ${ }^{43}$

627

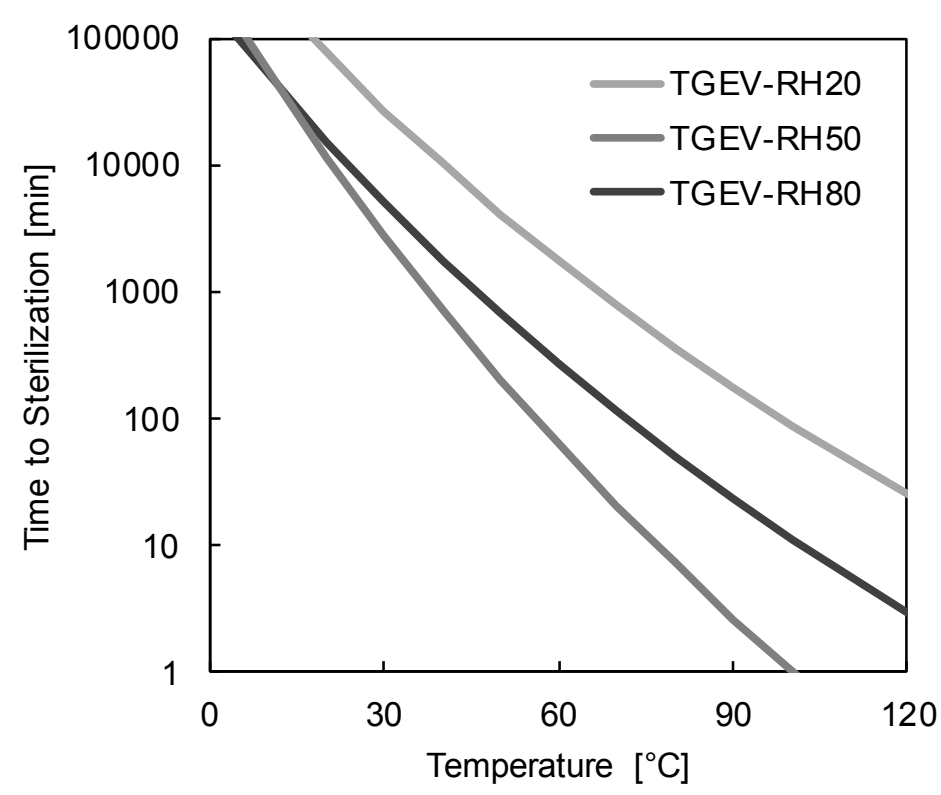

628

629 Figure S24. Model predictions for sterilization times required for TGEV at levels of relative humidity of $630 \quad 20 \%, 50 \%$, and $80 \%$.

631 


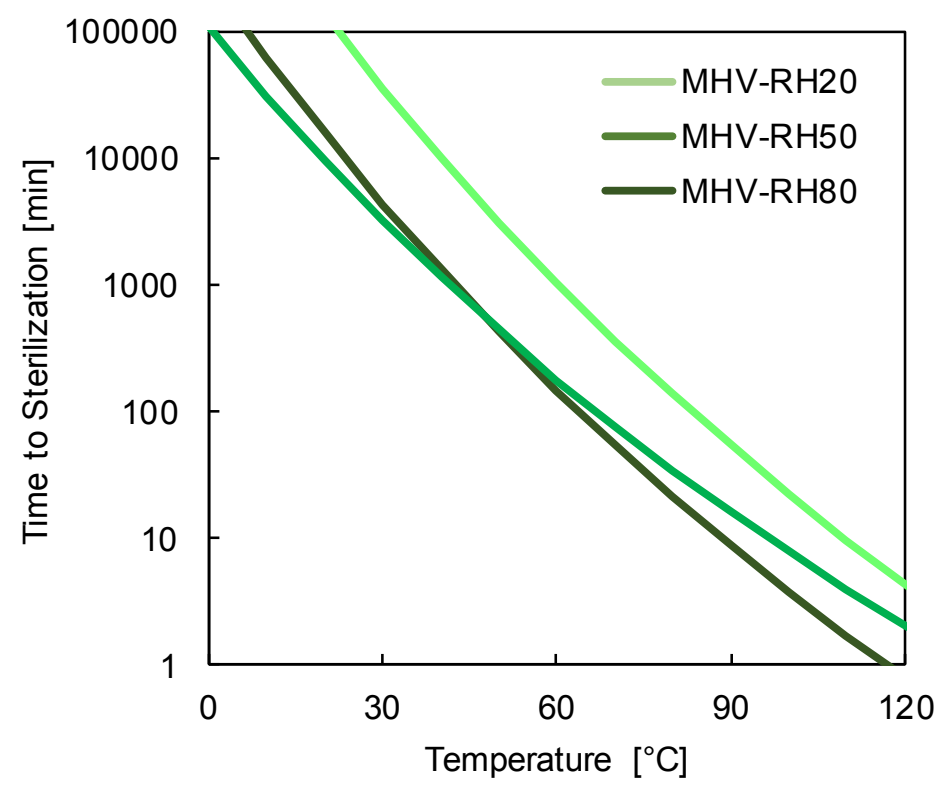

632

633 Figure S25. Model predictions for sterilization times required for MHV at levels of relative humidity of $63420 \%, 50 \%$, and $80 \%$.

635

\section{Trends across pH levels}

637 Comparing results for PEDV across $\mathrm{pH}$ levels of 7.2, 9.2, and 10.2, we observed a faster rate of virus 638 inactivation at more basic $\mathrm{pH}$ levels as reported in prior work, ${ }^{27}$ shown here in Figure $\mathbf{S 2 6}$. 


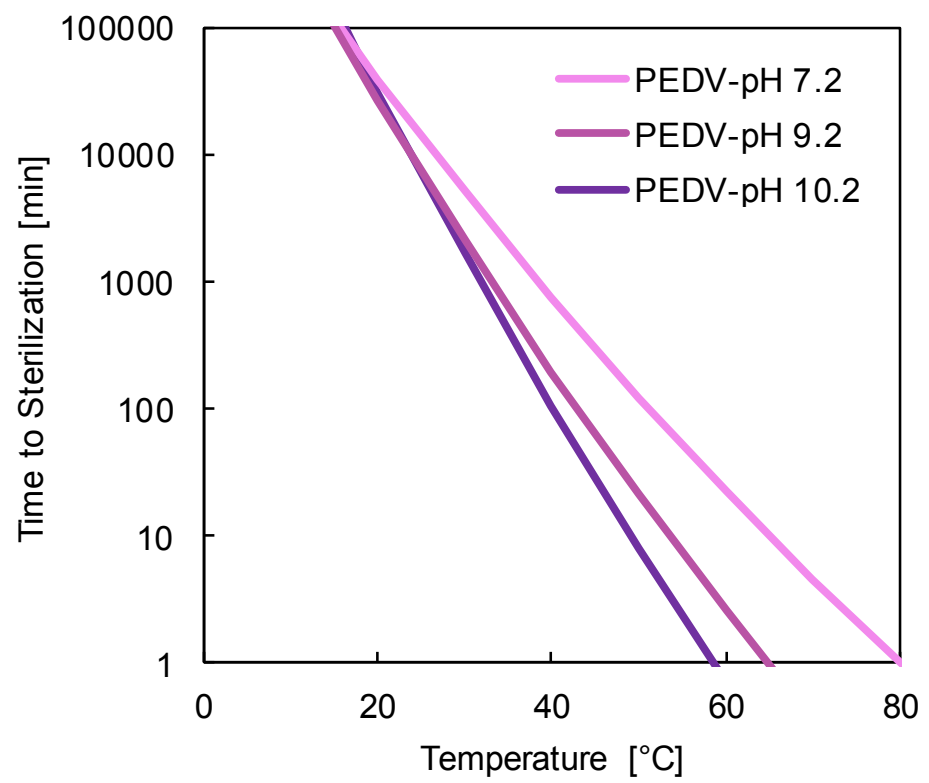

640

641 Figure S26. Model predictions for sterilization times required for PEDV at pH levels of 7.2, 9.2, and $642 \quad 10.2$

643

\section{S4. Conversion of Climate Data to Inactivation Timescale Map}

645 The national average temperature map of the United States for the months of January to March, 2020, was

646 obtained from the National Oceanic and Atmospheric Administration (NOAA). This temperature map,

647 shown in Figure S27, displays the CONUS mean temperature (except data for Hawaii and Alaska, which

648 were obtained from NOAA's climate data online search). The average temperature values encompassing

649 January through March, 2020, were chosen in accordance with the timeline of the COVID-19 pandemic

650 to date.

651 


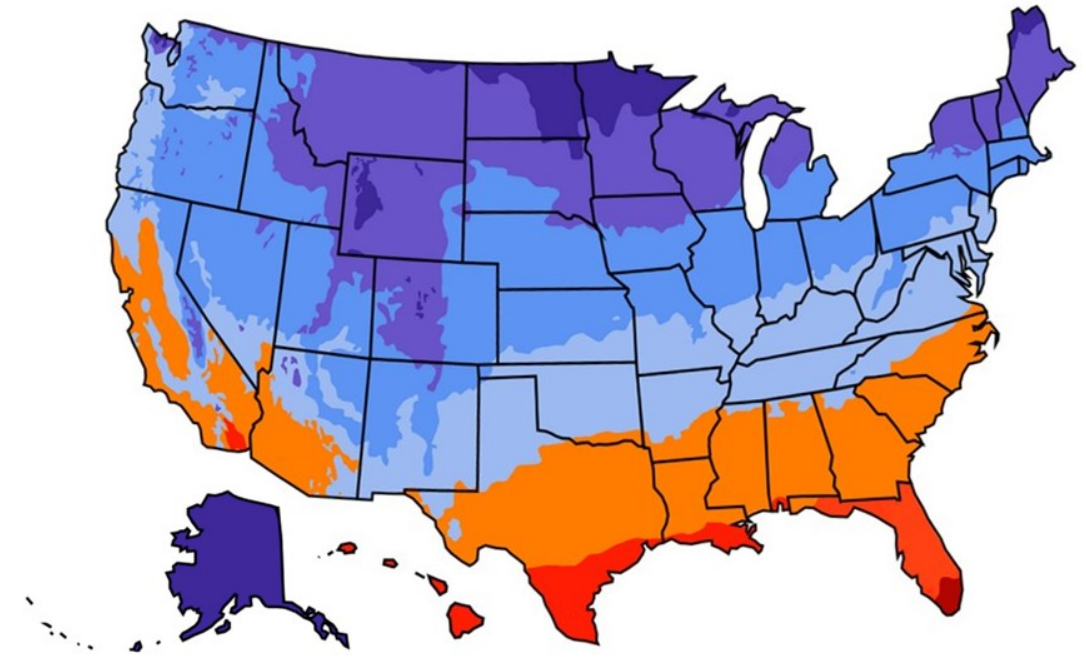

Avg. Temperature
$-12^{\circ} \mathrm{C}$
$-7{ }^{\circ} \mathrm{C}$
$-1{ }^{\circ} \mathrm{C}$
$20^{\circ}{ }^{\circ} \mathrm{F}$
$10^{\circ} \mathrm{C}$
$20^{\circ} \mathrm{C}$
$20^{\circ} \mathrm{F}$
$30^{\circ} \mathrm{F}$
$40{ }^{\circ} \mathrm{F}$
$50{ }^{\circ} \mathrm{F}$
$60{ }^{\circ} \mathrm{F}$
$70{ }^{\circ} \mathrm{F}$
$80^{\circ} \mathrm{F}$

653 Figure S27. Initial data from NOAA used to generate Figure 3 in the main text; average temperatures 654 over the period encompassing January to March, 2020, are shown. 